\title{
A Model of Competitive Stock Trading Volume
}

\section{Jiang Wang}

Massachusetts Institute of Technology

\begin{abstract}
A model of competitive stock trading is developed in which investors are heterogeneous in their information and private investment opportunities and rationally trade for both informational and noninformational motives. I examine the link between the nature of heterogeneity among investors and the behavior of trading volume and its relation to price dynamics. It is found that volume is positively correlated with absolute changes in prices and dividends. I show that informational trading and noninformational trading lead to different dynamic relations between trading volume and stock returns.
\end{abstract}

\section{Introduction}

Trading volume plays a minor role in conventional models of asset prices (e.g., Merton 1973; Lucas 1978). Part of this is justified under the representative agent paradigm. When the asset market is complete and there exists a representative agent, the resulting allocation is optimal and asset prices are determined purely by the aggregate risk. ${ }^{1}$ Trading in the market only reflects the allocation of the aggre-

I thank Andrew Alford, Bruce Grundy, Chi-fu Huang, Paul Pfleiderer, and Deborah Lucas and seminar participants at Cornell University, Massachusetts Institute of Technology, Princeton University, University of Alberta, University of British Columbia, University of California at Berkeley, University of Chicago, and University of Pennsylvania for helpful comments. I also thank José Scheinkman (the editor) and an anonymous referee for valuable suggestions. The support from the Nanyang Technological University Career Development Assistant Professorship and the International Financial Services Research Center at MIT is gratefully acknowledged.

${ }^{1}$ Market completeness is meant in the sense of Harrison and Kreps (1979). For a discussion on the representative agent models, see, e.g., Constantinides (1982, 1989). 
gate risk and the diversification of individual risks among investors. It provides no additional information about prices given characterizations of the aggregate risk. The weak empirical performance of the representative agent models has led researchers to develop models with heterogeneous investors and an incomplete asset market (see, e.g., Mankiw 1986; Scheinkman and Weiss 1986; Lucas 1991; Marcet and Singleton 1991; Campbell and Kyle 1993; Heaton and Lucas 1993; Wang 1993). With an incomplete asset market, both the aggregate and individual risks affect equilibrium prices, and the behavior of prices crucially depends on the nature of investor heterogeneity. In these models, quantity variables such as trading volume have important roles to play.

Investors trade among themselves because they are different. Thus the behavior of trading volume is closely linked to the underlying heterogeneity among investors. By examining the dynamic relation between volume and prices, one can study how the nature of investor heterogeneity determines the behavior of asset prices. In this paper, I develop an equilibrium model of stock trading in which investors are heterogeneous in their information and private investment opportunities and rationally trade for both informational and noninformational reasons. I use the model to study the behavior of stock trading volume and its relation with returns. It is shown that different heterogeneity among investors gives rise to different volume behavior and return-volume dynamics. This implies that trading volume conveys important information about how assets are priced in the market. My analysis has interesting empirical applications. For example, one challenge to models of heterogeneous investors is how to identify empirically the nature of the heterogeneity among investors. Prices alone are not sufficient to resolve this identification problem since heterogeneity such as differences in investors' financial constraints, nontraded income, information, and so forth is not directly observable. My results suggest that examining the joint behavior of return and volume can help one to learn about the underlying heterogeneity among investors.

I consider a simple economy in which there are both traded assets (a "stock" and a risk-free bond) and private investment opportunities. Investors have different private investment opportunities and different information about the stock's future dividends. The informed investors have private information about the stock's future dividends and the uninformed investors rationally extract information from realized dividends, prices, and public signals. They trade competitively in the stock market. The informed investors trade when they receive private information about the stock's future cash flow. This gives rise to their informational trading. They also trade to optimally 
rebalance their portfolio when their private investment opportunity changes. This gives rise to their noninformational trading. ${ }^{2}$ The uninformed investors trade only for noninformational reasons. They are willing to trade with the informed investors since not all the trades from the informed investors are information motivated. When a trade from the informed investors is perceived to be noninformational, the uninformed investors will take the other side at favorable prices and expect to earn abnormal future returns. I employ the model to analyze the behavior of equilibrium trading volume and how it is related to the dynamics of returns. I focus on the effect of information asymmetry on the behavior of volume.

Since the uninformed investors cannot perfectly identify the informed investors' motive behind each trade, they face the risk of trading against informed investors' private information. As the information asymmetry between the two classes of investors increases, the adverse selection problem of the uninformed investors worsens and trading volume decreases.

In the current model, trading is always accompanied by price changes since investors are risk averse. When a group of investors sell their stock shares to rebalance their portfolio, for example, the price of the stock must drop in order to induce other investors to buy. As information asymmetry increases, the uninformed investors demand a higher discount in price when they buy the stock from the informed investors in order to cover the risk of trading against private information. Therefore, trading volume is always positively correlated with absolute price changes and the correlation increases with information asymmetry.

My model also implies that under asymmetric information, public news about the stock's future dividends generates abnormal trading. Without information asymmetry, the price fully adjusts to reflect any new information about future dividends. When investors have different private information, however, they update their expectations differently in response to public information about future dividends. The difference in their response to the same information generates trading. The greater the information asymmetry, the larger the abnormal trading volume when public news arrives. ${ }^{3}$

\footnotetext{
${ }^{2}$ This somewhat abuses the terminology since investors trade only when there is new information either about the stock's future cash flow or about other variables of the economy (investors' wealth, preferences, other investment opportunities, etc.). In this sense, all trades are information generated.

${ }^{3}$ If investors are heterogeneous in other aspects such as preferences, tax status, etc., changes in price due to public information can also generate trading (see, e.g., Dumas 1989; Michaely and Vila 1993).
} 
My model captures two types of heterogeneity among investors: heterogeneous investment opportunities and asymmetric information. These two types of heterogeneity give rise to different dynamic relations between volume and returns. Without information asymmetry, investors trade only to rebalance their portfolios when their private investment opportunity changes. In this case, trading is always accompanied by changes in the current price, which are followed by price changes in the opposite direction. For example, when some investors sell their shares for portfolio reasons, the volume must be accompanied by a price decrease to attract other investors. The price decrease, however, has nothing to do with the stock's future dividends, which are the same as before. Thus the current price drop and high volume increase expected future returns. ${ }^{4}$

With information asymmetry, however, the uninformed investors can be trading against the informed investors' private information. As the true state of the economy is revealed, the uninformed investors realize the mistakes in their previous trading and trade to revise their positions. In addition, they take on new positions as they perceive new needs of noninformational trading from the informed investors. These two components in the trading of the uninformed investors lead to a different dynamic relation between return and volume. In the former situation, a high realized return reveals that the uninformed investors have underestimated the value of the stock and underinvested in the stock. Thus they buy more shares and the expected future return increases. In the latter situation, a high realized return reflects a price increase due to the buying pressure of the informed investors for noninformational reasons. But the price increase is not related to the stock's future dividends. Thus the uninformed investors sell their shares at the high price and the expected future return decreases. Since volume does not distinguish the sign of a trade, the implication of current return and volume on future returns is different depending on which of the two components dominates. A high return accompanied by high volume implies high future returns if the first component dominates and low future returns if the second component dominates. Clearly, the first component arises only when there is informational trading. Therefore, informational trading and noninformational trading give rise to a very different dynamic relation between volume and returns.

The literature on stock trading volume is extensive. There are many empirical studies on the relation between volume and price

\footnotetext{
${ }^{4}$ Campbell, Grossman, and Wang (1993) study this type of dynamic return-volume relation under symmetric information.
} 
changes, earnings announcements, and serial correlation in returns. ${ }^{5}$ Various models have been suggested to shed light on trading in general and on some of the empirical regularities. Huffman (1987) and Campbell et al. (1993), for example, consider competitive models in which investors with homogeneous information trade since they have different preferences or constraints (see also Scheinkman and Weiss 1986; Dumas 1989). Pfleiderer (1984) considers a competitive model in which investors have diverse information about the true value of the stock and behave myopically. ${ }^{6}$ Kyle (1985), Admati and Pfleiderer (1988), and Foster and Viswanathan $(1990,1993)$, among others, consider noncompetitive models of stock trading in which a few investors have superior information about the stock and trade strategically to maximize profits.

The current model assumes competitive markets. It extends the existing competitive models in two important ways. First, it is a fully dynamic model in which investors follow dynamic trading strategies to maximize lifetime expected utilities. This enables us to look at the dynamic behavior of trading volume and its relation with return dynamics. Second, it models both informational and noninformational trading as investors' optimizing behavior. This differs from the noisy rational expectations models commonly used to study information heterogeneity in asset markets. In these models, noninformational trading is introduced into the economy as "liquidity trading" (or "noise trading") without actually modeling its economic origin. This approach is not preferable in studying the behavior of volume since the noninformational component is exogenous. It also becomes problematic in welfare analysis.

The rest of the paper is organized as follows. Section II describes the general model. I solve for the equilibrium of the model in Section III. In Sections IV, V, and VI, I analyze the behavior of trading volume, the relation between volume and contemporaneous changes in prices and dividends, and the dynamic relation between volume and returns. Section VII provides some further comments.

\footnotetext{
${ }^{5}$ Karpoff (1987) provides a survey on the empirical relation between volume and contemporaneous price changes. Beaver (1968), Kiger (1972), and Bamber (1986), e.g., present evidence on abnormal trading on earnings announcement days. Morse (1980), Gallant, Rossi, and Tauchen (1992), LeBaron (1992), and Campbell et al. (1993) examine the dynamic relation between aggregate volume and returns.

${ }^{6}$ Other models of competitive security trading with information heterogeneity include Copeland (1976), Karpoff (1986), Grundy and McNichols (1989), and Kim and Verrecchia (1991). These models (with the exception of those of Copeland and Karpoff) use the noisy rational expectations framework. A different approach to model competitive stock trading assumes that investors have different beliefs (or models) concerning the stock's future cash flow. Varian (1985), Harris and Raviv (1993), and Kandel and Pearson (1993) follow this approach.
} 


\section{The Model}

Let us consider a simple economy with a single good that can be either consumed or invested. There are two classes of investors in the economy, which I call the I-investors and the U-investors. The two classes of investors are different in their information about the state of the economy and their private investment opportunities. Let the fraction of I-investors be $\omega$ and that of U-investors $1-\omega(0 \leq$ $\omega \leq 1)$. The economy is further defined as follows.

\section{A. Preferences}

All investors have constant absolute risk aversion (CARA). They maximize expected utility of the following form:

$$
E_{t}\left\{-\sum_{s=0}^{\infty} \beta^{s} e^{-\gamma c_{t+s}}\right\},
$$

where $E_{t}$ is the expectations operator conditional on the investors' information at time $t$, and $c_{t+s}$ is consumption in period $t+s$. I have assumed that all investors have the same time discount factor $\beta$ and risk aversion parameter $\gamma$.

\section{B. Investment Opportunities}

There are only two publicly traded assets in the economy, a riskless asset and a risky asset ("stock"). ${ }^{7}$ The riskless asset is assumed to have an infinitely elastic supply at a positive constant rate of return $r$. Let $R=1+r$ be the gross rate of return on the riskless asset.

Each share of the stock pays a dividend $D_{t}$ at time $t$. The dividend $D_{t}$ is governed by the process

$$
D_{t}=F_{t}+\epsilon_{D, t},
$$

where $F_{t}$ follows an $\mathrm{AR}(1)$ process:

$$
F_{t}=a_{F} F_{t-1}+\epsilon_{F, t}, \quad 0 \leq a_{F} \leq 1 .
$$

Here, $\epsilon_{D, t}$ and $\epsilon_{F, t}$ are independently and identically distributed (i.i.d.) shocks to $D_{t}$ and $F_{t}$, respectively; $F_{t}$ is the persistent component in dividends and $\epsilon_{D, t}$ is the idiosyncratic component; and $F_{t}$ (the "funda-

\footnotetext{
${ }^{7}$ Restricting the securities traded in the market makes the market incomplete. This is necessary to prevent the equilibrium prices from fully revealing all private information. Note, however, that market incompleteness is not sufficient to prevent fully revealing prices. In Grossman (1976), e.g., the market is incomplete but prices do provide a sufficient statistic to all the private information in the market.
} 
mental" of the stock) fully determines the expectation of future dividends. ${ }^{8}$

Shares of the stock are perfectly divisible and are traded at no cost in a competitive stock market. Without loss of generality, assume the total number of outstanding shares to be one. Let $P_{t}$ be the (exdividend) share price of the stock. Each period, the stock yields a dividend $D_{t}$ and a capital gain $P_{t}-P_{t-1}$. Define $Q_{t}$ to be the excess return on one share of stock, which is the return minus the financing cost at the risk-free rate: $Q_{t} \equiv P_{t}+D_{t}-R P_{t-1}$. Note that $Q_{t}$ is the excess return on one share of stock instead of the excess return on one dollar invested in the stock. The former is the excess share return and the latter is the excess rate of return. One has to divide the share return by the share price to get the rate of return. In the remainder of this paper, I use the term "share return" for convenience.

In addition to publicly traded assets, there is a risky production technology that is available only to the I-investors. ${ }^{9}$ The technology has constant returns to scale. If $I_{t}$ units are invested in the technology at time $t$, the total payoff at time $t+1$ will be $I_{t}\left(1+r+q_{t+1}\right)$, where $q_{t+1}$ is the excess rate of return for period $t+1$. Let

$$
q_{t+1}=Z_{t}+\epsilon_{q, t+1},
$$

where $Z_{t}$ is the expected excess rate of return and $\epsilon_{q, t+1}$ is the i.i.d. random shock to the return. Assume that $Z_{t}$ follows an AR(1) process:

$$
Z_{t}=a_{Z} Z_{t-1}+\epsilon_{Z, t}, \quad 0 \leq a_{Z}<1 .
$$

The innovation $\epsilon_{Z, t}$ is assumed to be i.i.d. over time. Clearly, $Z_{t}$ determines the private investment opportunity of the I-investors.

\section{Information Structure}

All investors observe realized dividends and market prices of the stock. The I-investors have perfect private information about $F_{t}$ at time $t$ whereas the $\mathrm{U}$-investors receive only noisy signals about $F_{t}$ :

$$
S_{t}=F_{t}+\epsilon_{S, t},
$$

where $\epsilon_{S, t}$ is the i.i.d. noise in the signal. ${ }^{10}$

${ }^{8}$ Here, the dividend has an unconditional mean of zero. One can easily reinterpret $D_{t}$ defined by eqq. (1)-(2) as deviations in the dividend from its unconditional mean, which can be any positive constant.

${ }^{9}$ In more general cases, there can be a set of private investment opportunities. Different investors may have access to a different subset of them. I shall discuss this generalization in Sec. VII.

${ }^{10}$ One can consider the more general case in which the $\mathrm{U}$-investors receive signals about past values of $F_{t}$ as well as its current value: $S_{t}^{(n)}=F_{t-n}+\epsilon_{S, t}^{(n)}(n=0,1, \ldots$, 
Assume further that $Z_{t}$ is known to the I-investors. Since the Uinvestors have no access to the private technology, it is assumed that they have no private information about its returns (except the prior distribution). This is assumed just for simplicity of the exposition. One can generalize the model and allow those investors who are excluded from production to have some information about its returns.

Since the I-investors are better informed than the U-investors, they can be called, respectively, the informed and the uninformed investors. Let ${ }_{t}^{i}$ be the information set of the informed investors at time $t$ and $\eta_{t}^{u}$ that of the uninformed investors. Then

$$
\eta_{t}^{i}=\left\{D_{s}, P_{s}, F_{s}, Z_{s} \mid s \leq t\right\}, \quad \eta_{t}^{u}=\left\{D_{s}, P_{s}, S_{s} \mid s \leq t\right\} .
$$

Here I have chosen the initial point of the economy to be $-\infty$. I also assume that the prior of all investors is normal.

The precision of public signals determines the information asymmetry between the informed and the uninformed investors. In the remainder of the paper, I use $\sigma_{S}^{2} \equiv \operatorname{var}\left(\epsilon_{S, t}\right)$ as a measure of information asymmetry. When $\sigma_{s}^{2}=0, S_{t}$ perfectly reveals $F_{t}$ to the uninformed investors. In this case, information is symmetric. As $\sigma_{s}^{2}$ increases, the public signal becomes less informative and the information asymmetry between the two classes of investors increases.

The structure of the economy is common knowledge.

\section{Distributional Assumptions}

Assume that all the shocks $\epsilon_{D, t}, \epsilon_{F, t}, \epsilon_{Z, t}, \epsilon_{q, t}$, and $\epsilon_{S, t}$ are jointly normal and i.i.d. over time. Normality is assumed purely for mathematical tractability. Define the vector of shocks $\epsilon_{t}$ as $\epsilon_{t}^{T}=\left(\epsilon_{D, t}, \epsilon_{F, t}, \epsilon_{Z, t}, \epsilon_{q, t}\right.$, $\left.\boldsymbol{\epsilon}_{S, t}\right)$. Then $\boldsymbol{\epsilon}_{t} \sim N(0, \boldsymbol{\Sigma})$. Here $\boldsymbol{\Sigma}$ is the covariance matrix of the shocks. For simplicity, assume in the remainder of the paper that all the shocks are uncorrelated except $\epsilon_{D, t}$ and $\epsilon_{q, t}$. As will become clear, general correlation structures can be easily incorporated into the model, leading qualitatively to the same results.

To fix ideas, we shall restrict ourselves to the case in which $\sigma_{D, q} \equiv$ $\operatorname{cov}\left(\epsilon_{D, t}, \epsilon_{q, t}\right)>0$. Thus the returns on the stock are positively correlated with the returns on the private technology. In this case, investing in the stock and investing in the private technology are substitutes to the I-investors. If the expected return on the private

$\tau): S_{t}^{(0)}$ is the signal about the current value of $F_{t}$ and $S_{t}^{(n)}, n=1, \ldots, \tau$, are signals about its past values. One can interpret $S_{t}^{(0)}$ as earnings announcements and $S_{t}^{(n)}(n>$ 0 ) as annual reports, etc. When $\tau=1$ and $S_{t}^{(1)}=F_{t-1}$ (i.e., $\epsilon_{t}^{(1)}=0$ ), the true value of $F_{t}$ is revealed after one lag. This is the case in which the I-investors' private information is short-lived. In the general case in which public signals are noisy, private information is long-lived. 
technology is high, the I-investors will increase their investment in the private technology and decrease their investment in the stock.

\section{Equilibrium}

Let us now consider the equilibrium of the model defined in Section II. The model captures two types of heterogeneity among investors: heterogeneity in investment opportunities and heterogeneity in information. Their impact on the equilibrium is different. Let us first consider the simple case of symmetric information in which investors are heterogeneous only in their investment opportunities. In this case, investors trade only for noninformational reasons when their private investment opportunity changes. We shall use this case to analyze the noninformational trading among investors and its impact on the stock price. We shall then consider the case with heterogeneity in both information and investment opportunities. Investors trade for both informational and noninformational reasons. We shall examine the effect of information asymmetry on investors' portfolio policies and the equilibrium price.

\section{A. Symmetric Information}

Suppose that $\sigma_{S}^{2}=0$ and the public signal $S_{t}$ perfectly reveals the persisent component of dividend $F_{t}$. In this case, investors have homogeneous information about the stock's future dividends but different private investment opportunities. The I-investors constantly adjust their investment in the private technology as its expected return $Z_{t}$ changes. When the returns on their private investments are correlated with the returns on the stock, they also want to adjust their stockholdings at the same time to maintain the optimal risk-return trade-off. This generates their trading in the stock market and causes the stock price to vary. The actual price and volume can be derived by solving the equilibrium of the economy. Since the symmetric information is a special case of the general model solved in the next subsection, I shall state the results without proof in this subsection.

\section{Dividends Uncorrelated with Returns on Private Investments}

Let us first consider the case in which future dividends are uncorrelated with returns on private investments (i.e., $\sigma_{D q}=0$ ). When there is no uncertainty in future dividends $\left(\sigma_{D}^{2}=\sigma_{F}^{2}=0\right), D_{t}=F_{t}$. The stock is the same as a coupon bond. Its price is simply the present value of future dividends discounted at the risk-free rate: $\sum_{\tau=1}^{\infty} R^{-\tau} D_{t+\tau}=a F_{t}$, where $a=a_{F} /\left(R-a_{F}\right)$. 
When there is uncertainty in the stock's future dividends, a premium is required to compensate the risk in future dividends. The equilibrium price is

$$
P_{t}^{A}=E_{t}\left[\sum_{\tau=1}^{\infty} R^{-\tau} D_{t+\tau}\right]-p_{0}^{A}=a F_{t}-p_{0}^{A},
$$

where $p_{0}^{A}=\alpha\left[(1+a)^{2} \sigma_{F}^{2}+\sigma_{D}^{2}\right]>0$. Here $\alpha=\gamma r / R$ is the intertemporal risk aversion coefficient. The first term in the price function is the present value of expected future dividends discounted at the risk-free rate. The second term, $p_{0}^{A}$, is the discount on the price to compensate the risk in future dividends. It increases with investors' risk aversion and the variance in future dividends. Given the equilibrium price, the expected excess return on the stock is $E_{t}\left[Q_{t+1}\right]=$ $r p_{0}^{A}>0$, which is constant over time. As new information arrives about future dividends, the stock price adjusts to fully reflect the information. But the expected excess return stays the same.

Investors' optimal investments in the stock and the private technology depend on the expected returns. Let $X_{t}^{i}$ and $X_{t}^{u}$ be the stock shares held by an I-investor and a U-investor, respectively, and $y_{t}$ be an I-investor's investment in the private technology. It is easy to show that in the current case, $X_{t}^{i}=X_{t}^{u}=E_{t}\left[Q_{t+1}\right] / \alpha \sigma_{Q}^{2}$ and $y_{t}=Z_{t} / \alpha \sigma_{q}^{2}$. Here, $\sigma_{Q}^{2}=\operatorname{var}_{t}\left(Q_{t+1}\right)$ is the conditional variance of excess stock returns. When the expected return on the private production changes, the I-investors change their investments in the private technology but not their holdings of the stock since the two returns are uncorrelated. Investors' holdings of the stock remain constant over time and there is no trading.

\section{Dividends Correlated with Returns on Private Investments}

When dividends and returns on the private technology are positively correlated (i.e., $\sigma_{D q}>0$ ), the I-investors' stock demand depends not only on the expected return on the stock but also on the expected return on their private investments. Investments in the stock and in the private technology become substitutes to the I-investors. When the expected return on the private technology is high, for example, they invest more in it to earn higher returns and less in the stock to control the risk of their overall portfolio. As the private investment opportunity changes over time, the I-investors optimally adjust their private investments and stockholdings. This need of portfolio rebalancing generates their trading in the stock market. 
When the I-investors sell (buy) the stock to rebalance their portfolios, the price of the stock has to drop (rise) to attract the U-investors. The price drop rewards the $\mathrm{U}$-investors for bearing more risk by taking on additional shares. Note that this price change occurs without any change in the stock's future dividends. Therefore, the equilibrium stock price depends not only on its expected future dividend $F_{t}$ but also on the expected return on I-investors' private investments $Z_{t}$. In this case, the equilibrium stock price is

$$
P_{t}^{B}=a F_{t}-\left(p_{0}^{B}+p_{Z}^{B} Z_{t}\right),
$$

where $p_{0}^{B}>0$ and $p_{Z}^{B}>0$.

The expected excess share return on the stock is then $E_{t}\left[Q_{t+1}\right]=$ $r p_{0}^{B}+\left(R-a_{Z}\right) p_{Z}^{B} Z_{t}$, which increases with the expected return on the private technology. It can be shown that the stockholding of the $U$ investors linearly depends on $E_{t}\left[Q_{t+1}\right]$ and that of the I-investors linearly depends on both $E_{t}\left[Q_{t+1}\right]$ and $E_{t}\left[q_{t+1}\right]=Z_{t}$ (see the next subsection). Thus as $Z_{t}$ increases, the I-investors sell the stocks to rebalance their portfolio. The price of the stock decreases and the U-investors absorb the extra shares as the expected stock return increases. This gives rise to noninformational trading in the current model.

\section{B. Asymmetric Information}

Let us now consider the equilibrium in which investors are heterogeneous in both their information and investment opportunities. ${ }^{11}$ The I-investors are endowed with private information about the state of the economy. The underlying state variables of the economy are $F_{t}$ and $Z_{t}: F_{t}$ determines the stock's future cash flow and $Z_{t}$ determines the private investment opportunity. They both affect the stock price, as we have seen in the case of symmetric information. Under asymmetric information, however, $F_{t}$ and $Z_{t}$ do not fully characterize the state of the economy. The equilibrium depends not only on the true values of the underlying state variables but also on the uninformed investors' expectations of these variables. Since $F_{t}$ and $Z_{t}$ are not publicly observable, the uninformed investors rationally extract information about their values based on realized dividends, prices, and public signals. Let $\hat{F}_{t} \equiv E_{t}^{u}\left[F_{t}\right]$ be the uninformed investors' conditional expectation of $F_{t}$, where $E_{t}^{u}[\cdot] \equiv E_{t}\left[\cdot \mid p_{t}^{u}\right]$. The uninformed investors

\footnotetext{
${ }^{11}$ For discussions on the rational expectations equilibrium with heterogeneously informed investors, see Green (1973), Grossman (1976), and Grossman and Stiglitz (1980).
} 
form their stock demand on the basis of $\hat{F}_{t}$. Consequently, the equilibrium stock price depends not only on $F_{t}$ and $Z_{t}$ but also on $\hat{F}_{t}{ }^{12}$

Therefore, under information asymmetry, the state of the economy is determined by $F_{t}, Z_{t}$, and $\hat{F}_{t}$, which in turn determine the equilibrium stock price. The equilibrium of the economy in general depends on the initial conditions of the economy. Since the initial point is $-\infty$, the economy is translationally invariant in time. Thus we shall consider only steady-state equilibria of the economy. We have the following result.

Proposition 1. The economy defined in Section II has a steadystate rational expectations equilibrium in which the equilibrium stock price is

$$
P_{t}=-p_{0}+\left(a-p_{F}\right) \hat{F}_{t}+p_{F} F_{t}-p_{Z} Z_{t},
$$

where $p_{0}, p_{Z}>0$ and $0 \leq p_{F} \leq a$.

\section{Proof. See Appendix A.}

The equilibrium price takes a linear form similar to the one in the case of symmetric information. Both the informed and the uninformed investors' expectations of future dividends, $F_{t}$ and $\hat{F}_{t}$, respectively, enter the price function. Note that the market-clearing price does not fully reveal the informed investors' private information. Bad news about future dividends (low $F_{t}$ ) or good private investment opportunities (high $Z_{t}$ ) can cause both the informed investors to sell the stock and its price to drop. Observing the price (as well as the dividend and the public signal) is not sufficient for the uninformed investors to identify the two factors. Therefore, information asymmetry persists in the equilibrium.

Given the equilibrium price, let us now consider investors' expectations of the stock's future returns and their optimal investment policies. We shall first derive the conditional expectation of the uninformed investors and then solve for the optimal portfolios of both the informed and the uninformed investors.

\section{Conditional Expectations of the Uninformed Investors}

The uninformed investors form their expectations on the basis of observations of dividends, public signals, and prices. Realized dividends and signals provide information about future dividends (i.e., $F_{t}$ ), whereas equilibrium prices provide information about both fu-

\footnotetext{
${ }^{12}$ One might think of $\hat{Z}_{t} \equiv E_{t}^{u}\left[Z_{t}\right]$ as another state variable, and price should be a function of $F_{t}, Z_{t}$, and $\hat{F}_{t}$ as well as $\hat{Z}_{t}$. I shall show later that within the class of linear equilibria considered in this paper, $\hat{Z}_{t}$ is a redundant variable given $F_{t}, Z_{t}$, and $\hat{F}_{t}$.
} 
ture dividends and the private investment opportunity of the informed investors. In particular, from the current price the uninformed investors can infer the following sum: $p_{F} F_{t}-p_{Z} Z_{t} \equiv \Pi_{t}$, since $P_{t}=-p_{0}+\left(a-p_{F}\right) \hat{F}_{t}+\Pi_{t}$ and $\hat{F}_{t}$ is their own expectation. Thus $\Pi_{t}$ represents the information content of the equilibrium price.

We have assumed that $F_{t}$ and $Z_{t}$ both follow Gaussian processes. In addition, dividends, public announcements, and equilibrium prices are linear signals about $F_{t}$ and $Z_{t}$ with normally distributed noise. Under these conditions, the calculation of conditional distributions of unobserved state variables is a linear filtering problem. We have the following result.

Theorem 1. Given $\eta_{t}^{u}=\left\{D_{s}, P_{s}, S_{s}: s \leq t\right\}$, the conditional expectations, $\hat{F}_{t}=E_{t}^{u}\left[F_{t}\right]$ and $\hat{Z}_{t}=E_{t}^{u}\left[Z_{t}\right]$, are determined by the following Kalman filtering equation:

$$
\left(\begin{array}{l}
\hat{F}_{t} \\
\hat{Z}_{t}
\end{array}\right)=\left(\begin{array}{l}
E_{t-1}^{u}\left[F_{t}\right] \\
E_{t-1}^{u}\left[Z_{t}\right]
\end{array}\right)+\mathbf{k}\left(\begin{array}{c}
S_{t}-E_{t-1}^{u}\left[S_{t}\right] \\
D_{t}-E_{t-1}^{u}\left[D_{t}\right] \\
\Pi_{t}-E_{t-1}^{u}\left[\Pi_{t}\right]
\end{array}\right),
$$

where $\mathbf{k}$ is a $2 \times 3$ matrix $\left(k_{11}, k_{12}, k_{13}, k_{21}, k_{22}>0\right.$ and $\left.k_{23}<0\right)$.

Proof. See Appendix A.

The intuition behind the filtering equation is simple. The first term on the right-hand side gives the expectation based on previous information. The second term gives the update in expectations based on new information from surprises in price, dividend, and signal. Since $E_{t-1}^{u}\left[F_{t}\right]=a_{F} \hat{F}_{t-1}$ and $E_{t-1}^{u}\left[Z_{t}\right]=a_{Z} \hat{Z}_{t-1}$, equation (10) is a difference equation of $\hat{F}_{t}$ and $\hat{Z}_{t}$. The innovations to the expectations are linear in the innovations to the signals. For example, an unexpected high dividend $\left(D_{t}-E_{t-1}^{u}\left[D_{t}\right]>0\right)$ is attributed partially to an increase in $F_{t}$. Similarly, the uninformed investors increase their expectation of $Z_{t}$ with unexpected price decreases. Furthermore, their expectation of $Z_{t}$ also increases with unexpected high dividends and public signals given the equilibrium prices. Note that the equilibrium price reveals the linear difference of $F_{t}$ and $Z_{t}: \Pi_{t}=p_{F} F_{t}-p_{Z} Z_{t}$. Thus

$$
p_{F} \hat{F}_{t}-p_{Z} \hat{Z}_{t}=p_{F} F_{t}-p_{Z} Z_{t} \text {. }
$$

Any information in dividends and public signals that increases the expectation of $F_{t}$ also increases the expectation of $Z_{t}$.

Let $\Theta_{t} \equiv \hat{F}_{t}-F_{t}$, where $\Theta_{t}$ represents the error of the uninformed investors in estimating $F_{t}$. Similarly, $\hat{Z}_{t}-Z_{t}$ represents the error in estimating $Z_{t}$. Equation (11) implies that $p_{F}\left(\hat{F}_{t}-F_{t}\right)=p_{Z}\left(\hat{Z}_{t}-Z_{t}\right)$. Thus the two errors are perfectly correlated. If $F_{t}$ is over- (under-) estimated, so is $Z_{t}$. It can be shown that $\Theta_{t}$ follows an $\operatorname{AR}(1)$ process 
with zero unconditional mean:

$$
\Theta_{t}=a_{\Theta} \Theta_{t-1}+\epsilon_{\Theta, t},
$$

where $\epsilon_{\Theta, t}$ is linear in the underlying shocks $\epsilon_{t}$, and $0 \leq a_{\Theta}<1$ (see App. A). The fact that $\Theta_{t}$ is mean-reverting to zero implies that the estimation error of the uninformed investors is expected to be corrected eventually. For example, the uninformed investors rationally attribute an unexpected increase of dividend in the current period partly to an increase in its persistent component $F_{t}$. If, however, it is actually due to an idiosyncratic shock, the uninformed investors would be overestimating future dividends. New realizations of dividends, signals, and prices will then be lower than expected. The uninformed investors will update their expectations on the basis of the new information and lower their estimate $\hat{F}_{t}$. Note that the flow of new information does not eliminate the information asymmetry in a steady state since the state of the economy is changing over time and the uninformed investors are "chasing" a moving target. Define $\varepsilon \equiv$ $\operatorname{var}\left(\Theta_{t}\right)$ to be the unconditional variance of the uninformed investors' estimation error. It reflects the information asymmetry between the two classes of investors, and $\varepsilon=0$ under symmetric information.

\section{Excess Stock Returns}

Given the equilibrium price and the solution to the conditional expectation of the uninformed investors, we can derive investors' expectations of future returns on the stock. The excess stock return $Q_{t+1}$ consists of both dividends and capital gains: $Q_{t+1}=D_{t+1}+P_{t+1}-$ $R P_{t}$. From equations (9) and (10), we have

$$
Q_{t+1}=e_{0}+e_{Z} Z_{t}-e_{\Theta} \Theta_{t}+\epsilon_{Q, t+1},
$$

where $\epsilon_{Q, t+1}$ is linear in $\epsilon_{t+1}, e_{0}=r p_{0} \geq 0, e_{Z}=\left(R-a_{F}\right) p_{Z} \geq 0$, and $e_{\Theta}=\left(R-a_{\Theta}\right)\left(a-p_{F}\right) \geq 0$. Since the unconditional expectations of $Z_{t}$ and $\Theta_{t}$ are zero, $e_{0}=E\left[Q_{t+1}\right]$ is the unconditional expectation of excess stock returns.

The informed investors' expectation of excess stock returns depends on the expected return on the private technology $Z_{t}$ and the uninformed investors' estimation error $\Theta_{t}$ :

$$
E_{t}^{i}\left[Q_{t+1}\right]=e_{0}+e_{Z} Z_{t}-e_{\Theta} \Theta_{t} .
$$

Here, $Z_{t}$ affects the stock's price and expected returns since it affects the informed investors' demand for the stock; $\Theta_{t}$ affects the expected returns since it provides profitable opportunities for the informed investors. When $\Theta_{t}>0$, for example, the uninformed investors are overestimating expected future dividends. As $F_{t}$ becomes revealed 
next period, the uninformed investors will revise their expectations and the price will decrease. With superior information, the informed investors can forecast the correction of the uninformed investors' expectation and the corresponding price change. Thus a positive $\Theta_{t}$ implies an expected price decrease and, hence, a low expected return by the informed investors.

For the uninformed investors, $E_{t}^{u}\left[\Theta_{t}\right]=E_{t}^{u}\left[\hat{F}_{t}-F_{t}\right]=0$. Their expectation of excess stock returns depends only on their estimation of the expected return on the private technology of the informed investors:

$$
E_{t}^{u}\left[Q_{t+1}\right]=e_{0}+e_{Z} \hat{Z}_{t} .
$$

Changes in $Z_{t}$ change the expected stock returns for reasons discussed above. However, the uninformed investors do not observe the true value of $Z_{t}$. They can form expectations only on the basis of realized prices, dividends, and signals. Their expected return depends on their expectation of $Z_{t}$ instead of the true value of $Z_{t}$. As a result, innovations in dividends and public signals can change the uninformed investors' expected returns even though they are uncorrelated with the true value of $Z_{t}$.

Furthermore, changes in expected returns are correlated with realized returns on the stock. A positive shock in $Z_{t}$ leads to a decrease in the current stock price and a low realized return on the stock. At the same time it gives high expected returns on the private technology in the next period. It also increases the expected future returns on the stock since the price has decreased but the stock's future cash flow has not.

\section{Optimal Portfolios}

Given the expected returns on the stock and the private technology, we can now derive the investors' optimal investment policies. The informed investors' portfolio consists of investments in the risk-free asset, the stock, and the private technology. The uninformed investors invest only in the risk-free asset and the stock. Solving the optimization problem of both the informed and the uninformed investors, we have the following results.

Theorem 2. Let $W_{t}^{i}$ be an informed investor's wealth at time $t, c_{t}^{i}$ his consumption, $X_{t}^{i}$ his stock shares, $y_{t}$ his investment in the private production, and $J^{i}$ his value function. His optimization problem is

$$
J^{i} \equiv \max _{c^{i}, X^{i}, y} E\left[-\sum_{s=0}^{\infty} \beta^{s} e^{-\gamma c_{t+s}} \mid \rho_{t}^{i}\right]
$$




$$
\text { subject to } W_{t+1}^{i}=\left(W_{t}^{i}-c_{t}\right) R+X_{t}^{i} Q_{t+1}+y_{t} q_{t+1} \text {. }
$$

It has the following solution:

$$
\begin{gathered}
J^{i}\left(W_{t}^{i} ; Z_{t}, \Theta_{t} ; t\right)=-\beta^{t} e^{-\alpha W_{t}^{i}-V^{i}\left(Z_{t}, \Theta_{t}\right)}, \\
c_{t}^{i}=-\frac{1}{\gamma} \ln \left(-\frac{1}{\gamma} \frac{\partial J^{i}}{\partial W}\right),
\end{gathered}
$$

and

$$
\left(\begin{array}{c}
X_{t}^{i} \\
y_{t}
\end{array}\right)=\frac{1}{\alpha} \Gamma^{i}\left(\begin{array}{c}
E\left[Q_{t+1} \mid g_{t}^{i}\right] \\
E\left[q_{t+1}||_{t}^{i}\right]
\end{array}\right)-\frac{1}{\alpha}\left(\begin{array}{c}
h_{X}^{i}\left(Z_{t}, \Theta_{t}\right) \\
h_{y}^{i}\left(Z_{t}, \Theta_{t}\right)
\end{array}\right),
$$

where $\alpha=r / \gamma R, V^{i}(\cdot, \cdot)$ is a quadratic function, $\Gamma^{i}$ is a $2 \times 2$ positive definite matrix of constants, and $h_{X}^{i}(\cdot, \cdot)$ and $h_{y}^{i}(\cdot, \cdot)$ are linear functions. ${ }^{13}$

Theorem 3. Let $W_{t}^{u}$ be an uninformed investor's wealth at time $t$, $c_{t}^{u}$ his consumption, $X_{t}^{u}$ his stock shares, and $J^{u}$ his value function. His optimization problem is

$$
\begin{gathered}
J^{u} \equiv \max _{c^{u}, X^{u}} E\left[-\sum_{s=0}^{\infty} \beta^{s} e^{-\gamma c_{t+s}^{u}} \mid g_{t}^{i}\right] \\
\text { subject to } W_{t+1}^{u}=\left(W_{t}^{u}-c_{t}^{u}\right) R+X_{t}^{u} Q_{t+1} .
\end{gathered}
$$

It has the following solution:

$$
\begin{gathered}
J^{u}\left(W_{t}^{u} ; \hat{Z}_{t} ; t\right)=-\beta^{t} e^{-\alpha W_{t}^{u}-V u\left(\hat{Z}_{t}\right),} \\
c_{t}^{u}=-\frac{1}{\gamma} \ln \left(-\frac{1}{\gamma} \frac{\partial J^{u}}{\partial W}\right),
\end{gathered}
$$

and

$$
X_{t}^{u}=\frac{1}{\alpha} \Gamma^{u} E\left[Q_{t+1} \mid g_{t}^{u}\right]-\frac{1}{\alpha} h_{X}^{u}\left(\hat{Z}_{t}\right),
$$

where $V^{u}(\cdot)$ is a quadratic function, $\Gamma^{u}$ is a positive constant, and $h_{X}^{u}(\cdot)$ is a linear function. ${ }^{14}$

${ }^{13}$ A transversality condition of the Merton type is imposed to obtain a solution to the optimization problem (see Merton [1969] and App. A).

${ }^{14}$ For a discussion on the optimization problem with partially observed state variables, see Fleming and Rishel (1975). With the distributional assumptions in the current model, the separation principle applies (see, e.g., Detemple 1986; Dothan and Feldman 1986; Gennotte 1986). In this case, the estimation problem and the optimization prob- 
Proof. See Appendix A.

The optimal portfolios are composed of two components. The first component is a mean-variance efficient portfolio reflecting the tradeoff between expected return and risk. The terms $\Gamma^{i}$ and $\Gamma^{u}$ are, respectively, the inverses of the renormalized covariance matrix of returns for the informed investors and the uninformed investors. This differs from the well-known results in continuous-time models in which no renormalization of the covariance matrix is needed (see Merton [1990] for results on dynamic portfolio rules in continuous time). The difference arises from the lack of continuous trading opportunities in a discrete setting. The second component is a hedging portfolio reflecting investors' hedging needs. In the current model, expected returns on both the stock and the private investment technology change over time. Since returns on the stock are correlated with changes in expected future returns, it provides a vehicle to hedge against changes in future investment opportunities.

\section{Stock Trading Volume}

As shown in the previous section, investors' optimal portfolios depend on their investment opportunities. Heterogeneity among investors generates trading as they adjust their portfolios when their expectations and investment opportunities change.

\section{A. Trading Strategies}

In order to better understand the behavior of trading volume, let us first examine investors' trading strategies that are determined by their optimal portfolios. We can reexpress the investors' optimal stockholdings in terms of the variables that determine their investment opportunities. For the informed investors,

$$
\begin{aligned}
X_{t}^{i} & =\frac{1}{\alpha}\left[\Gamma_{11}^{i} E_{t}^{i}\left[Q_{t+1}\right]+\Gamma_{12}^{i} E_{t}^{i}\left[q_{t+1}\right]-h_{X}^{i}\left(Z_{t}, \Theta_{t}\right)\right] \\
& =f_{0}^{i}+f_{Z}^{i} Z_{t}+f_{\Theta}^{i} \Theta_{t},
\end{aligned}
$$

where $f_{0}^{i}, f_{Z}^{i}$, and $f_{\Theta}^{i}$ are constants. The informed investors trade in the stock market as $Z_{t}$ and $\Theta_{t}$ change. The term $Z_{t}$ determines the expected return on the private technology. Changes in $Z_{t}$ give rise to their noninformational trading as in the case of symmetric informa-

lem are separable. We can first solve the estimation problem and then use the estimates as the actual state variables to solve the optimization problem. The optimization problem has the standard Markov property. 
tion. On the other hand, $\Theta_{t}$ gives the error of uninformed investors in estimating future dividends, which causes the stock price to deviate from its "fundamental value." The informed investors observe these price deviations and take speculative positions against expected future corrections. As $\Theta_{t}$ changes, the deviation in the price also changes and the informed investors revise their speculative positions. This gives rise to their informational trading in the stock market.

Now consider the trading of the uninformed investors. Their optimal stockholding can be expressed as

$$
X_{t}^{u}=\frac{1}{\alpha}\left[\Gamma^{u} E_{t}^{u}\left[Q_{t+1}\right]-h^{u}\left(\hat{Z}_{t}\right)\right]=f_{0}^{u}+f_{Z}^{u} \hat{Z}_{t},
$$

where $f_{0}^{u}$ and $f_{Z}^{u}$ are constants. The uninformed investors know that they are trading only with the informed investors. They are still willing to trade because not all the trades are made against informed investors' superior information. The informed investors also trade to rebalance their portfolios. In these cases, the uninformed investors are perfectly willing to take the other side of the trade at favorable prices and earn abnormal returns. In the case of informational trades, of course, they lose. Under information asymmetry, they cannot perfectly identify the motive of the informed investors behind each trade. The best they can do is to trade only when they expect the trade to be noninformational on the basis of their information. As shown by equation (21), their optimal stockholding changes only when their expectation of the informed investors' private technology $Z_{t}$ changes: $X_{t}^{u}-X_{t-1}^{u}=f_{Z}^{u}\left(\hat{Z}_{t}-\hat{Z}_{t-1}\right)$.

The change in the uninformed investors' expectation of $Z_{t}$ can be decomposed into two parts:

$$
\begin{aligned}
\hat{Z}_{t}-\hat{Z}_{t-1} & =E_{t}^{u}\left[Z_{t}\right]-E_{t-1}^{u}\left[Z_{t-1}\right] \\
& =\left[E_{t}^{u}\left[Z_{t-1}\right]-E_{t-1}^{u}\left[Z_{t-1}\right]\right]+\left[E_{t}^{u}\left[Z_{t}\right]-E_{t}^{u}\left[Z_{t-1}\right]\right] .
\end{aligned}
$$

The first part is the change in expectation about the previous value of $Z$ given the new dividend, public signal, and price; the second part is the expectation of change in $Z$ from its previous value. Accordingly, we can decompose the trading of the uninformed investors:

$$
X_{t}^{u}-X_{t-1}^{u}=f_{Z}^{u}\left\{\left[E_{t}^{u}\left[Z_{t-1}\right]-E_{t-1}^{u}\left[Z_{t-1}\right]\right]+\left[E_{t}^{u}\left[Z_{t}\right]-E_{t}^{u}\left[Z_{t-1}\right]\right]\right\} \text {. }
$$

The first component is associated with correcting errors in previous trading as new information arrives. The second component is associated with taking new positions as $Z_{t}$ changes from its previous value. Clearly, under symmetric information, $E_{t}^{u}\left[Z_{t-1}\right]=E_{t-1}^{u}\left[Z_{t-1}\right]=Z_{t-1}$, and the first component is zero. Thus the first component reflects the uninformed investors' trading against the superior information 
of the informed investors. Suppose, for example, that in period $t-$ 1 the uninformed investors expect $Z_{t-1}$ to be high on the basis of $D_{t-1}, P_{t-1}$, and $S_{t-1}$. This implies that the informed investors are increasing their private investments and selling the stock. Hence, the stock price is low because of the selling pressure and the expected return is high. The uninformed investors increase their position in the stock on the basis of this expectation. Next period if the new dividend, public signal, and price indicate that $Z_{t-1}$ is lower than previously expected, the uninformed investors realize that they have overestimated $Z_{t-1}$ and future returns of the stock and have overinvested in the stock. Consequently, they will sell the stock to correct the bad trades made previously.

\section{B. Trading Volume}

Given the investors' trading strategies, it is easy to calculate the equilibrium trading volume. Since we have normalized the total number of shares outstanding to one, what we refer to as trading volume is actually the turnover. In the current model, we have only two classes of investors, and all the trading takes place between the two classes. The trading volume $V_{t}$ can be calculated from changes in the holdings of either the informed or the uninformed investors. For simplicity, we follow the uninformed investors:

$$
V_{t}=(1-\omega)\left|X_{t}^{u}-X_{t-1}^{u}\right|=(1-\omega)\left|f_{t}^{u}\right|\left|\hat{Z}_{t}-\hat{Z}_{t-1}\right| .
$$

With the normality assumption about the underlying shocks, we have

$$
\begin{aligned}
\bar{V} \equiv E\left[V_{t}\right] & =2(1-\omega)\left|f_{Z}^{u}\right| \sqrt{\frac{2}{\pi}} \operatorname{var}\left(\hat{Z}_{t}-\hat{Z}_{t-1}\right), \\
\operatorname{var}\left(V_{t}\right) & =(\pi-1 / 2) \bar{V}^{2} .
\end{aligned}
$$

The variance of trading volume increases quadratically with its mean. Since volume is determined by absolute changes in investors' stockholdings, it exhibits positive serial correlation.

We can examine the effect of information asymmetry on trading volume by increasing the noise in the public signal. Figure $1 a$ shows that volume generally decreases with $\sigma_{s}^{2} .{ }^{15}$ Increasing $\sigma_{s}^{2}$ has two consequences: (1) to make the signal $S_{t}$ less informative and (2) to increase the information asymmetry between the two classes of investors. Both have the effect of reducing volume. When $S_{t}$ becomes noisier, the uninformed investors have less information about the

\footnotetext{
${ }^{15}$ The parameter values in all the figures have been chosen arbitrarily. The patterns are quite robust with respect to changes in parameter values.
} 


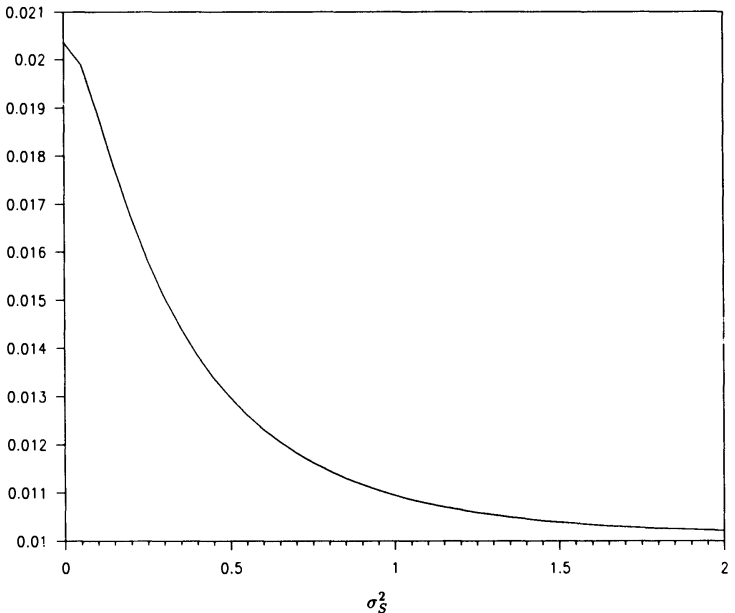

$\Gamma^{u}$

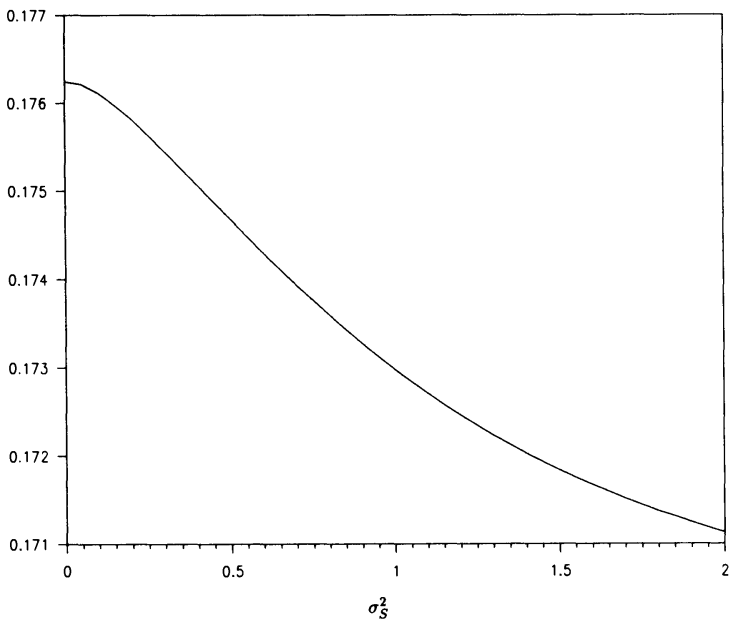

FIG. 1. $-a, \bar{V}$ plotted against $\sigma_{S}^{2} ; b, \Gamma^{u}$ plotted against $\sigma_{S}^{2} \cdot \gamma=1.0, \beta=0.9, r=0.2$, $\omega=0.1, a_{F}=0.9, a_{Z}=0.9, \sigma_{D}^{2}=2.0, \sigma_{F}^{2}=2.0, \sigma_{Z}^{2}=1.5, \sigma_{q}^{2}=1.0, \sigma_{D q}=0.6$. 
state of the economy, including the value of $Z_{t}$. As a result, $Z_{t}$ becomes less variable and they trade less on average. The general intuition behind this result is best seen by considering the extreme case in which all information sources, including dividends and prices, are infinitely noisy. The uninformed investors will then simply hold a constant share of the stock and not trade at all.

Under asymmetric information, the uninformed investors face adverse selection problems when they trade with the informed investors. They cannot perfectly distinguish an informational trade from a noninformational trade. As the information asymmetry increases, the adverse selection problem of the uninformed investors becomes more severe. They face more uncertainty in identifying noninformational trades. As a result, they trade less aggressively against perceived changes in $Z_{t}$ in order to reduce possible losses. Formally, this is reflected in the fact that $\Gamma^{u}$ decreases when $\sigma_{S}^{2}$ increases. As equation (21) shows, $\Gamma^{u}$ characterizes how the uninformed investors change their stockholdings as the expected stock return changes. Figure $1 b$ illustrates the relation between $\Gamma^{u}$ and $\sigma_{s}^{2}$.

Clearly, our result crucially depends on the hierarchic information structure assumed in the model. In the more general case in which each class of investors may have some information that others do not have, the relation between volume and information heterogeneity can be different (see, e.g., Pfleiderer 1984; He and Wang 1992).

\section{Trading Volume and Changes in Prices and Dividends}

In this section, we shall examine how trading volume is related to absolute changes in prices and dividends and how these relations are affected by information asymmetry.

To simplify notation, let $\delta Y_{t}=Y_{t}-Y_{t-1}$ be the change in random variable $Y_{t}$. Thus $\delta P_{t}=P_{t}-P_{t-1}, \delta D_{t}=D_{t}-D_{t-1}$, and $\delta \hat{Z}_{t}=\hat{Z}_{t}-$ $\hat{Z}_{t-1}$. The correlations between volume and absolute changes in prices and dividends are, respectively

$$
\rho_{V_{t}, \delta P_{t} \mid} \equiv \frac{\operatorname{cov}\left(V_{t},\left|\delta P_{t}\right|\right)}{\sqrt{\operatorname{var}\left(V_{t}\right) \operatorname{var}\left(\left|\delta P_{t}\right|\right)}}
$$

and

$$
\rho_{V_{t},\left|\delta D_{t}\right|} \equiv \frac{\operatorname{cov}\left(V_{t},\left|\delta D_{t}\right|\right)}{\sqrt{\operatorname{var}\left(V_{t}\right) \operatorname{var}\left(\left|\delta D_{t}\right|\right)}} .
$$

As discussed earlier, volume is proportional to the absolute changes in the uninformed investors' expectation of $Z_{t}: V_{t} \propto\left|\delta \hat{Z}_{t}\right|$. Under the 
distributional assumptions about the underlying shocks, $\delta P_{t}, \delta D_{t}$, and $\delta \hat{Z}_{t}$ are jointly normal. Thus

$$
\rho_{V_{t}, \delta Y_{t} \mid}=\left(1-\frac{2}{\pi}\right)\left(1-\sqrt{1-\rho_{\delta \hat{t}_{t}, \delta Y_{t}}^{2}}\right) \geq 0, \quad \delta Y_{t}=\delta P_{t} \text { or } \delta D_{t} .
$$

The correlation is always nonnegative and is positive whenever $\delta \hat{Z}_{t}$ and $\delta Y_{t}$ are correlated, that is, $\rho_{\delta \hat{z}_{t}, \delta Y_{t}} \neq 0$.

\section{A. Correlation between Volume and Absolute Price Changes}

Let us first consider the correlation between trading volume and absolute price changes. In the current model, volume is always correlated with absolute price changes. This is best seen from the case of symmetric information. In this case, $\hat{Z}_{t}=Z_{t}$ and $P_{t}=-p_{0}+a F_{t}-p_{z} Z_{t}$. Thus $\operatorname{cov}\left(\delta Z_{t}, \delta P_{t}\right)=-2 p_{Z} \sigma_{Z}^{2}<0$. Here, trading is generated by investors' needs to rebalance their portfolios as their private investment opportunity changes. Since investors are risk averse, reallocation of the stock is always accompanied by price changes in our model.

Under asymmetric information, similar results hold. However, the uninformed investors face the adverse selection problem when they trade with the informed investors. There is always the risk that the informed investors are trading the stock for private information on future dividends instead of for portfolio rebalancing. As a result, an additional premium is required by the uninformed investors to accommodate the informed investors. For a given size trade, the price has to adjust more than in the case of symmetric information. As a result, the correlation between volume and absolute price changes increases with information asymmetry. From equation (25), we have the following result.

THEOREM 4. In the current model, $\rho_{V_{t},\left|\delta P_{t}\right|}>0$ when $\sigma_{D q} \neq 0$ and trading volume is positively correlated with absolute price changes.

Figure 2 illustrates the relation between $\rho_{V_{t},\left|\delta P_{t}\right|}$ and $\sigma_{S}^{2}$. Empirical evidence shows that trading volume is positively correlated with the absolute value of contemporary price changes. ${ }^{16}$ Our result is consistent with the empirical evidence.

\section{B. Correlation between Volume and Absolute Dividend Changes}

Let us now consider the correlation between trading volume and absolute changes in dividends. Clearly, changes in $D_{t}$ convey new

${ }^{16}$ See, e.g., the survey of Karpoff (1987) and the references therein. 


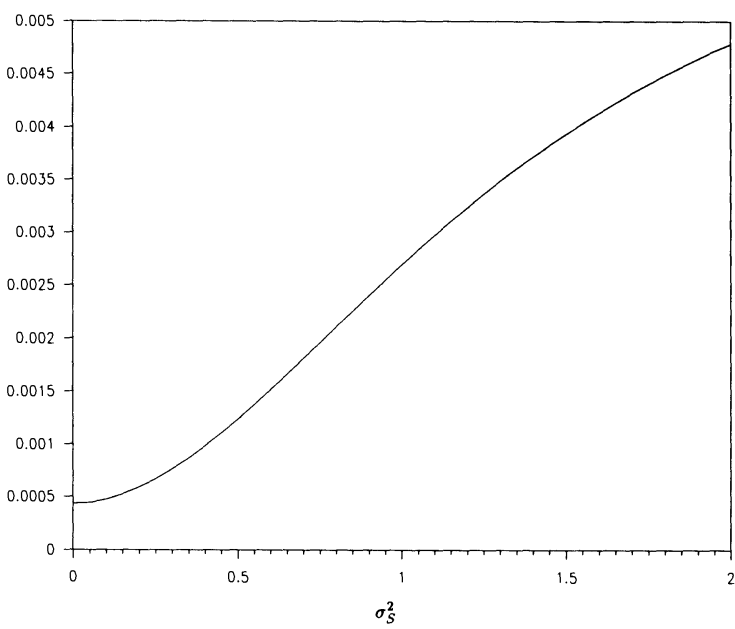

FIG. 2. $-\rho_{V_{t},\left|\delta P_{t}\right|}$ plotted against $\sigma_{S}^{2} \cdot \gamma=1.0, \beta=0.9, r=0.2, \omega=0.1, a_{F}=0.9, a_{Z}$ $=0.9, \sigma_{D}^{2}=2.0, \sigma_{F}^{2}=2.0, \sigma_{Z}^{2}=1.5, \sigma_{q}^{2}=1.0, \sigma_{D q}=0.6$.

information about the stock's future dividends. Hence, the question here is whether public information about the stock's future payoffs generates trading.

In the case of symmetric information, the true state of the economy is known to all investors. Changes in expectations about the stock's future dividends change only its current price but not its expected return. Therefore, new information about the stock's future payoffs does not generate trading. Trading occurs only when the private investment opportunity changes and the I-investors rebalance their portfolios. Formally, $\hat{Z}_{t}=Z_{t}$ and $\rho_{\delta Z_{t}, \delta D_{t}}=0$ since shocks to $Z_{t}$ are uncorrelated with shocks to dividends. Thus $\rho_{V_{t},\left|\delta D_{t}\right|}=0$ from equation (25).

In the case of asymmetric information, uninformed investors do not have perfect information about the informed investors' motive for trading. They take positions in the stock on the basis of their expectation about the informed investors' current private investment opportunity. As the new dividend, price, and public signal reveal new information about the economy, the uninformed investors trade to correct previous errors and to establish new positions on the basis of expectations about the new state. From equation (22),

$$
\begin{aligned}
\operatorname{cov}\left(\delta X_{t}^{u}, \delta D_{t}\right)= & f_{Z}^{u}\left\{\operatorname{cov}\left[E_{t}^{u}\left[Z_{t-1}\right]-E_{t-1}^{u}\left[Z_{t-1}\right], \delta D_{t}\right]\right. \\
& \left.+\operatorname{cov}\left[E_{t}^{u}\left[Z_{t}-Z_{t-1}\right], \delta D_{t}\right]\right\} .
\end{aligned}
$$


It is easy to show that $\operatorname{cov}\left[E_{t}^{u}\left[Z_{t-1}\right]-E_{t-1}^{u}\left[Z_{t-1}\right], \delta D_{t}\right]=\left(a_{F} p_{F} / p_{Z}\right) \varepsilon$ $>0$; that is, the correction in the estimation of $Z$ by the uninformed investors is positively correlated with innovations in future dividends. The intuition is as follows. Suppose that the realized dividend at $t-$ 1 is low because of a negative idiosyncratic shock. The uninformed investors rationally infer that the low dividend is partially due to a negative permanent shock. Their estimate of the permanent component is lower than its true value; so is their estimate of $Z_{t-1}$ (since the errors in estimating $Z_{t-1}$ and $F_{t-1}$ are perfectly correlated). But the negative shock to $D_{t-1}$ is actually idiosyncratic, and $D_{t}$ is likely to be higher than $D_{t-1}$. When a positive $\delta D_{t}$ is observed, the uninformed investors realize that they have underestimated $F_{t-1}$ and $Z_{t-1}$. Accordingly, they increase their estimates, and $E_{t}^{u}\left[F_{t-1}\right]-E_{t-1}^{u}\left[F_{t-1}\right]$ and $E_{t}^{u}\left[Z_{t-1}\right]-E_{t-1}^{u}\left[Z_{t-1}\right]$ are both positive. Thus $E_{t}^{u}\left[F_{t-1}\right]-E_{t-1}^{u}\left[F_{t-1}\right]$ and $E_{t}^{u}\left[F_{t-1}\right]-E_{t-1}^{u}\left[F_{t-1}\right]$ are positively correlated with $\delta D_{t}$. It is also easy to show from theorem 1 that $\operatorname{cov}\left[E_{t}^{u}\left[Z_{t}-Z_{t-1}\right], \delta D_{t}\right]=0 .{ }^{17}$ Therefore, $\operatorname{cov}\left(\delta X_{t}^{u}, \delta D_{t}\right)=f_{Z}^{u}\left(a_{F} p_{F} / p_{Z}\right) \varepsilon>0\left(f_{Z}^{u}\right.$ is positive). The uninformed investors buy the stock when the dividend increases and sell when it decreases. The following theorem summarizes our result.

THEOREM 5. In the current model,

$$
\rho_{\delta X_{t}^{u}, \delta D_{t}}=\frac{a_{F} p_{F} \varepsilon}{p_{Z} \operatorname{var}\left(\delta \hat{Z}_{t}\right) \operatorname{var}\left(\delta D_{t}\right)} .
$$

Under symmetric information, $\varepsilon=0, \rho_{\delta X_{t}^{u}, \delta D_{t}}=\rho_{V_{t},\left|\delta D_{t}\right|}=0$, and trading volume is uncorrelated with absolute dividend changes. Under asymmetric information, $\varepsilon>0$ and $\rho_{\delta X_{t}^{u}, \delta D_{t}}>0$. The uninformed investors buy the stock when the dividend increases and sell when the dividend decreases. Hence, $\rho_{V_{t},\left|\delta D_{t}\right|}>0$, and volume is positively correlated with absolute dividend changes.

The intuition behind this result is quite general. When investors have private information, they respond to public information differently since they interpret it differently. The difference in the changes of their expectations generates trading among them. A similar analysis shows that surprises in the public signal about the stock's future dividends also generate trading. Therefore, in the current model, public information about the stock's future dividends generates abnormal volume only under asymmetric information. The abnormal volume is positively related to the degree of information asymmetry

${ }^{17}$ One should not confuse this result with the fact that $\hat{Z}_{t}$ depends on $D_{t}$ as well as $\Pi_{t}$ and $S_{t}$. Conditional on $\Pi_{t}=p_{F} F_{t}-p_{Z} Z_{t}, \hat{Z}_{t}$ does depend on $D_{t}$ since $D_{t}$ provides information about $F_{t}$. But the unconditional variance between $\hat{Z}_{t}$ and $D_{t}$ is zero since $D_{t}$ alone provides no information about $Z_{t}$. 


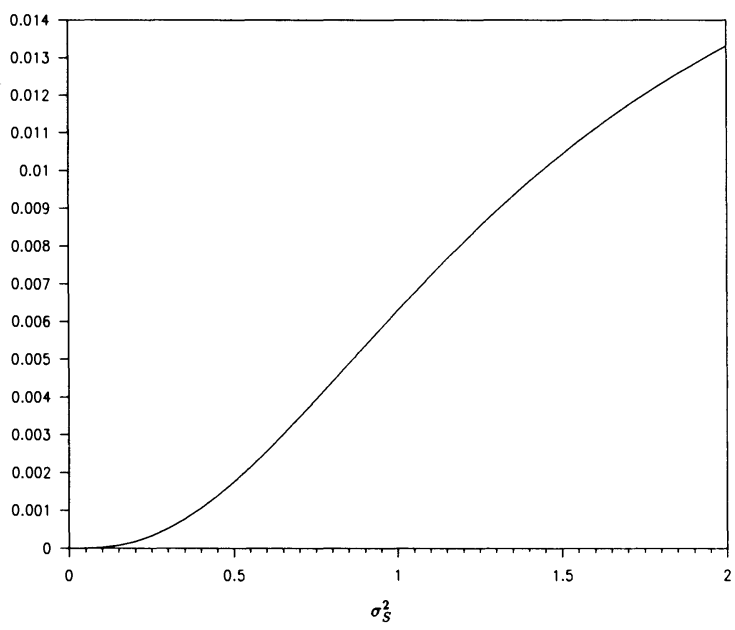

FIG. 3. $-\rho_{V_{t}\left|\delta D_{t}\right|}$ plotted against $\sigma_{S}^{2} \cdot \gamma=1.0, \beta=0.9, r=0.2, \omega=0.1, a_{F}=0.9, a_{Z}$ $=0.9, \sigma_{D}^{2}=2.0, \sigma_{F}^{2}=2.0, \sigma_{Z}^{2}=1.5, \sigma_{q}^{2}=1.0, \sigma_{D q}=0.6$.

in the market. Figure 3 shows how $\rho_{V_{t},\left|\delta D_{t}\right|}$ increases with $\sigma_{S}^{2}$, the noise in public signals as a measure of information asymmetry.

It has been documented that trading volume rises on the days of earnings announcements. ${ }^{18}$ This is consistent with the prediction of our model that volume is positively correlated with absolute dividend changes or the absolute value of $S_{t}{ }^{19}$ Moreover, it is found that the unexpected volume at the time of earnings announcements is larger for smaller-size firms. ${ }^{20}$ This is also consistent with our model if we assume that there is more information asymmetry in the market for small-size firms than for large-size firms.

\section{Dynamic Relation between Volume and Returns}

Empirical evidence suggests that volume, together with other information such as realized returns, can forecast future returns (see, e.g.,

${ }^{18}$ For empirical studies on the abnormal volume on announcement day, see, e.g., Beaver (1968), Kiger (1972), and Bamber (1986).

${ }^{19}$ When investors are heterogeneous in aspects other than information, such as preferences or tax status, they also react differently to public information.

${ }^{20}$ See, e.g., Bamber (1986). It is noted that for small firms, the announcement may contain more new information about firm earnings than for large firms. In other words, the unexpected component in earnings announcements may be inversely related to firm size. However, Bamber shows that after one controls for the size of the unexpected component, there is still a residual firm size effect. This residual firm size effect is what we are interested in here. 
Morse 1980; Gallant et al. 1992; LeBaron 1992; Campbell et al. 1993). For example, Campbell et al. find that at the aggregate level returns accompanied by high trading volume are more likely to be reversed than those accompanied by low volume. In what follows, we shall use the current model to study this type of dynamic relation between returns and volume. In particular, we shall focus on how information asymmetry affects the dynamic return-volume relation.

In the current model, trading occurs when the uninformed investors change their expectations about future stock returns. The trading volume directly reflects the amplitude of changes in their expectations. In addition, other public information such as current dividend and price provides information about the direction of these changes. Consequently, volume together with realized dividends and prices can predict future returns.

\section{A. Expected Future Excess Returns Conditional on Current Volume and Dividend Change}

We shall first study how trading volume and public news about the stock are related to future returns. Under symmetric information, public news about the stock's future dividends is immediately reflected in the price. The expected return on the stock stays the same, and there is no abnormal trading associated with the new information. Under asymmetric information, however, public information reveals the true state of the economy and the mistakes of the uninformed investors in previous estimation. The uninformed investors update their expectations and revise their previous trades. This generates abnormal trading with the news release. Together with the news, the volume provides information about expected future returns.

To be explicit, let us consider the expected future excess returns conditional on current volume and dividend changes. The following result holds.

Theorem 6. Let $\tilde{Q}_{t} \equiv Q_{t}-e_{0}$ be the abnormal excess return on the stock. Then

$$
E\left[\tilde{Q}_{t+1} \mid V_{t}, \delta D_{t}\right]=-e_{Z} \lambda_{V}^{D} \tanh \left(h_{D} V_{t} \delta D_{t}\right) V_{t} .
$$

Let $\phi_{D}=-e_{z} \lambda_{V}^{D} h_{D}$. Then

$$
E\left[\tilde{Q}_{t+1} \mid V_{t}, \delta D_{t}\right]=\phi_{D} V_{t}^{2} \delta D_{t}+\text { high-order terms }
$$

and $\phi_{D} \geq 0$. Under symmetric information, $\phi_{D}=0$. $^{21}$

${ }^{21}$ The proof is straightforward from the results given in App. B. 
Theorem 6 states that an increase in dividend accompanied by high volume implies high future returns. The intuition behind equation (27) is easy to understand. Changes in dividend can be anticipated or unanticipated. An anticipated dividend change contains no new information; hence, it does not affect the expectations of the uninformed investors and there is no trading accompanying it. An unanticipated change in current dividend contains new information about the stock's future dividends that affects the uninformed investors' expectations. There is trading accompanying it, and the expected return changes. Therefore, a dividend change accompanied by abnormal volume indicates that the change is unanticipated. Furthermore, good news (i.e., $\delta D_{t}>0$ ) implies that the uninformed investors have underestimated the stock's future returns. As a result, they will buy more shares of the stock and future returns will be higher. Bad news implies the opposite. This result is completely due to the information asymmetry between the two classes of investors.

\section{B. Expected Future Excess Returns Conditional on Current Volume and Return}

Let us now consider the expected future excess return of the stock conditional on its current excess return and trading volume. This would be an econometrician's forecast if he observes only realized excess returns and volume. ${ }^{22}$

Note that the excess return has two components: the dividend and the price change. The information content of a price change is different from that of a dividend. The current dividend provides information only about the stock's future dividends, whereas the price change provides information about the informed investors' noninformational trading as well as the stock's future dividends. We have just discussed the implication of a dividend change together with volume. Let us now focus on the implication of a price change with volume.

The intuition is best seen in the case of symmetric information when investors are heterogeneous only in their private investment opportunities. The stock price changes for two reasons: public information about its future dividends and changes in investors' private investment opportunities. In the former case, the price adjusts to fully reflect the new expectation of future dividends. There is no trading accompanying the price change, and the expected excess re-

\footnotetext{
${ }^{22}$ More precisely, an econometrician may observe both prices and dividends, which contain more information than just the returns. Here, for simplicity we use only the returns that also coincide with most of the empirical studies. They can also condition on the whole history of returns and volume. We shall discuss this later.
} 
turn on the stock remains the same. In the latter case, the price adjusts to reflect the I-investors' needs to trade and to attract the U-investors. There is trading accompanying the price change, and the expected future return changes in this case since the price has changed without changes in future dividends. Specifically, a price decrease (increase) accompanied by high volume is more likely due to the sale (purchase) by the I-investors than a decrease (increase) in future dividends. This implies high (low) future returns.

Therefore, whether abnormal volume is generated by the price change or by the dividend change leads to opposite predictions about future returns of the stock. Since the return aggregates the dividend and price change, the expectation conditional on current volume and excess return can be different depending on which of the two effects dominates. Formally, we have the following result.

Theorem 7. Given the current excess return and volume, next period's expected excess return is

$$
E\left[\tilde{Q}_{t+1} \mid \tilde{Q}_{t}, V_{t}\right]=e_{Z} E\left[Z_{t} \mid \tilde{Q}_{t}, V_{t}\right]=\lambda_{Q} \tilde{Q}_{t}-\lambda_{V} \tanh \left(h_{Q} V_{t} \tilde{Q}_{t}\right) V_{t} .
$$

Here, $\lambda_{Q}, \lambda_{V}$, and $h_{Q}$ are constants. ${ }^{23}$

Let $\phi_{0}=\lambda_{Q}$ and $\phi_{1}=h_{Q} \lambda_{V}$. The Taylor expansion of equation (29) yields

$$
E\left[\tilde{Q}_{t+1} \mid \tilde{Q}_{t}, V_{t}\right]=\left(\phi_{0}-\phi_{1} V_{t}^{2}\right) \tilde{Q}_{t}+\text { high-order terms }
$$

When $\phi_{1}>0$, returns accompanied by high volume are likely to be followed by returns in the opposite direction. When $\phi_{1}<0$, returns accompanied by high volume are likely to be followed by returns in the same direction.

We can now show that the sign of $\phi_{1}$ depends on the information asymmetry between the two types of investors. Let us first consider the case of symmetric information, that is, when $\sigma_{S}^{2}=0$ and all trades are noninformational. This case is similar to the situation considered by Campbell et al. (1993). The following result holds (see App. B).

TheOREM 8. Under symmetric information, $\phi_{1}>0$.

This result is obvious from the previous discussion. In this case, price changes provide new information about future excess returns but dividends do not.

Let us now consider the case with information asymmetry. Recall that under asymmetric information, the uninformed investors trade for two reasons: (1) to correct the errors made in previous trading when new information (such as changes in dividends) reveals the stock's true value and (2) to take new positions when price adjusts

${ }^{23}$ Here $E\left[\tilde{Q}_{t+1} \mid \tilde{Q}_{t}, V_{t}\right]=E\left[e_{Z} Z_{t}-e_{\Theta} \Theta_{t} \mid \tilde{Q}_{t}, V_{t}\right]$. Since $E_{t}^{u}\left[\Theta_{t}\right]=0$ and $\left\{\tilde{Q}_{t}, V_{t}\right\} \subset g_{t}^{u}$, $E\left[\Theta_{t} \mid \tilde{Q}_{t}, V_{t}\right]=0$. Thus $E\left[\tilde{Q}_{t+1} \mid \tilde{Q}_{t}, V_{t}\right]=e_{Z} E\left[Z_{t} \mid \tilde{Q}_{t}, V_{t}\right]$. 
to reflect the need of noninformational trading from the informed investors. These two components of trading are associated with different revisions in the uninformed investors' expectations as discussed above. Suppose that a trade is generated by an unanticipated low dividend, which implies that the uninformed investors overestimated future dividends in the previous period. They will lower their expectations on future stock returns. The correction in expectations gives rise to the sale of the stock by the uninformed investors accompanied by a low return in the current period as well as a decrease in expected future returns. Suppose that a trade is generated by the information that there is an increase in $Z_{t}$ and the informed investors are facing a good private investment opportunity. This then implies that they are selling the stock to adjust their portfolio. The uninformed investors will buy the shares as its price decreases. The expected change in $Z_{t}$ gives rise to the purchase of the stock by the uninformed investors accompanied by a decrease in the current price and an increase in expected future returns. Since volume does not distinguish the sign of a trade, these two components of the uninformed investors' trading generate a different dynamic relation between volume and return. If the first component dominates, a high volume accompanied by a low return implies a low return in the future. If the second component dominates, a high volume accompanied by a low return implies a high return in the future. It should be obvious that the first component exists only under asymmetric information when informed investors trade on private information.

Figure 4 shows that for some parameter values, $\phi_{1}$ becomes negative as $\sigma_{S}^{2}$ increases. This illustrates that in the case of severe information asymmetry, the dynamic volume-return relation can be very different from that in the case of symmetric information. Therefore, information asymmetry can qualitatively change the dynamic relation between return and volume. This implies that the dynamic returnvolume relation can reveal the nature of investor heterogeneity that affects asset prices.

\section{A Remark}

In the previous discussion, we considered only how the current return and volume predict future returns. More generally, the whole history of returns and volume can be used to predict future returns. This requires the calculation of the following conditional expectation:

$$
E\left[\tilde{Q}_{t+1} \mid\left\{\tilde{Q}_{s}, V_{s}: s \leq t\right\}\right]=e_{Z} E\left[Z_{t} \mid\left\{\tilde{Q}_{s}, V_{s}: s \leq t\right\}\right] .
$$

Calculating $E\left[Z_{t} \mid\left\{Q_{s}, V_{s}: s \leq t\right\}\right]$ is a nonlinear filtering problem. Even under the distributional assumption in the current setup, to solve the 


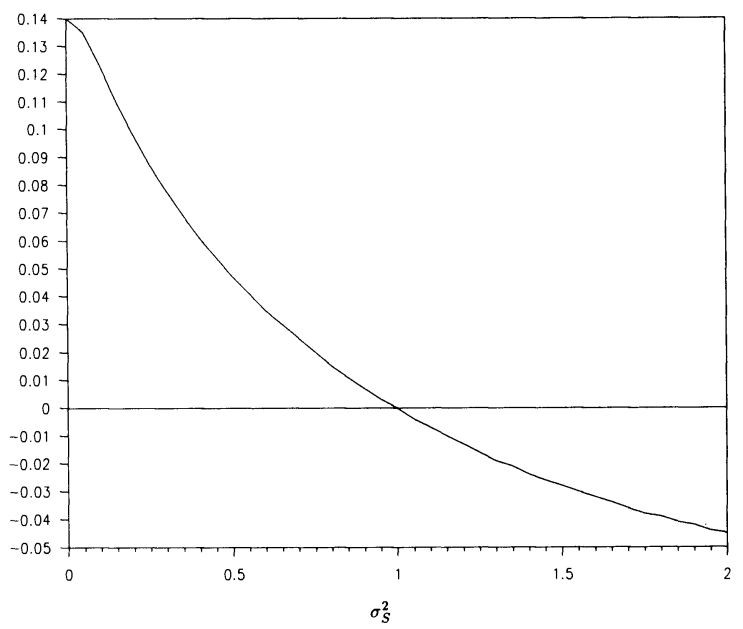

FIG. 4.- $\phi_{1}$ plotted against $\sigma_{S}^{2} \cdot \gamma=1.0, \beta=0.9, r=0.2, \omega=0.1, a_{F}=0.9, a_{Z}=$ $0.9, \sigma_{D}^{2}=2.0, \sigma_{F}^{2}=2.0, \sigma_{Z}^{2}=1.5, \sigma_{q}^{2}=1.0, \sigma_{D q}=0.6$.

nonlinear filter in closed form is a difficult task. One approach is to solve it recursively. Since the economy is stationary in the current setting, the importance of historical returns and volume in predicting future returns should diminish as they are further away from the present. For example, we can consider the expected excess future return conditional on the excess returns and volume of the last two periods. This is calculated in Appendix B. Take the Taylor expansion and keep the first two lowest-order terms. Then

$$
\begin{aligned}
E\left[\tilde{Q}_{t+1} \mid \tilde{Q}_{t}, V_{t} ; \tilde{Q}_{t-1}, V_{t-1}\right]= & -\left\{\lambda_{Q}^{(1)}+\lambda_{V}^{(1)}\left[h_{Q V}^{(1,1)} V_{t}^{2}+h_{Q V}^{(1,2)} V_{t-1}^{2}\right]\right\} \tilde{Q}_{t} \\
& -\left\{\lambda_{Q}^{(2)}+\lambda_{V}^{(2)}\left[h_{Q V}^{(2,1)} V_{t}^{2}+h_{Q V}^{(2,2)} V_{t-1}^{2}\right]\right\} \tilde{Q}_{t-1} .
\end{aligned}
$$

Here, $\lambda_{Q}^{(1)}, \lambda_{V}^{(1)}, \lambda_{Q}^{(2)}, \lambda_{V}^{(2)}, h_{Q V}^{(1,1)}, h_{Q V}^{(1,2)}, h_{Q V}^{(2,1)}$, and $h_{Q V}^{(2,2)}$ are constants given in Appendix B.

\section{Further Comments}

In this section, I provide a further discussion on the model developed above. I shall first comment on some generalizations of the model and then discuss some of its limitations.

In the model specified in Section II, only the informed investors 
have private investment opportunities. A more general setting would be to also give the uninformed investors private investment opportunities. They can be either the same as those of the informed investors or different. When the informed and the uninformed investors have the same technology, we have to assume that the informed investors have better information about the technology than the uninformed investors. For example, we can assume that the informed investors observe $Z_{t}$ and the uninformed investors observe only the realized returns. In this case, the investment opportunities, including both the traded and nontraded assets, are the same for both classes of investors. The only factor that generates trading is information given the incomplete market structure. However, it is the information concerning not only the stock's future cash flow, but also the returns to the private technology. When the informed and uninformed investors have different technologies, we do not have to assume that the informed investors have any private information on the uninformed investors' technology. In equilibrium, the price reveals the uninformed investors' private information to the informed investors, but the reverse is not true. Under these generalizations, most of our results remain unchanged.

A further generalization along the same line would be to allow each individual investor's private investment opportunity to be different (even within each group). In general, we can assume that the expected return to each investor's private investment opportunity has an aggregate component and an idiosyncratic component. The aggregate component is common to all investors and the idiosyncratic component is independent across investors. Since we have a large number of investors, only the aggregate shock to the private investment opportunities will affect the price and expected returns of the stock. This aggregate component will play exactly the same role as $Z_{t}$ in the current setup. The idiosyncratic shocks to the investors' investment opportunities give rise to only a noise component in the total trading volume.

Some other generalizations are straightforward. For example, we can allow the risk aversion to differ across investors as long as it remains in the CARA class. We can also extend the processes of $F_{t}$ and $Z_{t}$ to more general linear processes. Extending the current model to a multiasset world while maintaining the hierarchic information structure may also be interesting.

Despite the advantage of being tractable, the current model has many limitations. We assume that some investors have better information than others and they trade competitively in the market. We do not allow any form of information sale by the informed investors (see, 
e.g., Admati and Pfleiderer 1986, 1990). If the sale of information is feasible and costless, the assumed competitive behavior may lead to dissemination of information among investors. However, when the sale of information is costly, information asymmetry can be maintained in a competitive world.

We can model the noninformational trading as investors' rational behavior by introducing private investment opportunities. One can literally interpret them as investing in durables, human capital, nontraded assets, and so forth. But these factors at an individual level may not be the main driving force for daily trading in the market. When one thinks of large players in the market such as institutional investors, one would like to give the motive for noninformational trading a more general interpretation. This, however, requires more general specifications of objective functions, constraints, and so forth.

Another limitation of the current model comes from the hierarchic information structure. Information asymmetry takes the specific form that some investors are strictly better informed than others. In other words, there exists a strict ranking among the investors' information sets. As we have seen in the previous analysis, this form of information asymmetry intends to reduce trading among investors. Less informed investors simply become cautious when they trade with more informed investors. Pfleiderer (1984) considered a different information structure in which investors have diverse information about assets' future cash flows. In his model, diversity in the investors' information can actually increase volume. He and Wang (1992) consider a multiperiod model of trading under diverse private information. The actual information structure of the market may take much more general forms than what we assumed here.

\section{Appendix A}

\section{Proof of Theorems 1-3 and Proposition 1}

\section{A. Theorem 1}

The system of interest is the vector of underlying state variables: $\mathbf{z}_{t}^{T}=\left(F_{t}\right.$, $Z_{t}$ ), which follows the process

$$
\mathbf{z}_{t}=\mathbf{a}_{z} \mathbf{z}_{t-1}+\mathbf{b}_{z} \boldsymbol{\epsilon}_{t}
$$

where

$$
\mathbf{a}_{z}=\left(\begin{array}{cc}
a_{F} & 0 \\
0 & a_{Z}
\end{array}\right), \quad \mathbf{b}_{z}=\left(\begin{array}{l}
\mathbf{b}_{F} \\
\mathbf{b}_{Z}
\end{array}\right)
$$


Here, $\mathbf{b}_{F}=(0,1,0,0,0)$ and $\mathbf{b}_{Z}=(0,0,1,0,0)$. The signals are given by $\mathbf{s}_{t}^{T}=\left(S_{t}, D_{t}, \Pi_{t}\right)$ :

$$
\mathbf{s}_{t}=\mathbf{a}_{s} \mathbf{z}_{t}+\mathbf{b}_{s} \boldsymbol{\epsilon}_{t}
$$

where

$$
\mathbf{a}_{s}=\left(\begin{array}{cc}
1 & 0 \\
1 & 0 \\
p_{F} & p_{Z}
\end{array}\right), \quad \mathbf{b}_{s}=\left(\begin{array}{c}
\mathbf{b}_{S} \\
\mathbf{b}_{D} \\
0
\end{array}\right) .
$$

Here $\mathbf{b}_{S}=(0,0,0,0,1)$ and $\mathbf{b}_{D}=(1,0,0,0,0)$. The information set of the uninformed investors is $j_{t}^{u}=\left\{\mathbf{s}_{\tau} \mid \tau \leq t\right\}$. For notational simplicity, define $\boldsymbol{\Sigma}_{z z}=\mathbf{b}_{z} \boldsymbol{\Sigma} \mathbf{b}_{z}^{T}$ and $\boldsymbol{\Sigma}_{s s}=\mathbf{b}_{s} \boldsymbol{\Sigma} \mathbf{b}_{s}^{T}$.

The filtering problem is to derive the conditional distribution of the state variables given the history of signals. Under the current assumptions about the processes of $\mathbf{z}_{t}$ and $\mathbf{s}_{t}$, this is simply the Kalman filtering problem. Let $\hat{\mathbf{z}}_{t}$ $\equiv E\left[\left.\mathbf{z}_{t}\right|_{t} ^{q u}\right]$ and $\mathbf{o}_{t}=E\left[\left(\hat{\mathbf{z}}_{t}-\mathbf{z}_{t}\right)\left(\hat{\mathbf{z}}_{t}-\mathbf{z}_{t}\right)^{T}||_{t}^{u}\right]$. Then

$$
\begin{gathered}
\hat{\mathbf{z}}_{t+1}=\mathbf{a}_{z} \hat{\mathbf{z}}_{t}+\mathbf{k}_{t}\left[\mathbf{s}_{t+1}-E_{t}^{u}\left[\mathbf{s}_{t+1}\right]\right], \\
\mathbf{o}_{t}=\left(\mathbf{a}_{z} \mathbf{o}_{t-1} \mathbf{a}_{z}^{T}+\mathbf{\Sigma}_{z z}\right)-\mathbf{k}_{t} \mathbf{a}_{s}\left(\mathbf{a}_{z} \mathbf{o}_{t-1} \mathbf{a}_{z}^{T}+\mathbf{\Sigma}_{z z}\right),
\end{gathered}
$$

where

$$
\mathbf{k}_{t}=\left(\mathbf{a}_{z} \mathbf{o}_{t-1} \mathbf{a}_{z}^{T}+\boldsymbol{\Sigma}_{z z}\right) \mathbf{a}_{s}^{T}\left[\mathbf{a}_{s}\left(\mathbf{a}_{z} \mathbf{o}_{t-1} \mathbf{a}_{z}^{T}+\boldsymbol{\Sigma}_{z z}\right) \mathbf{a}_{s}^{T}+\boldsymbol{\Sigma}_{s s}\right]^{-1} .
$$

A derivation of Kalman filters can be found in, for example, Jazwinski (1970). We are interested only in steady-state solutions. ${ }^{24}$ Let $\mathbf{o}=\left\{o_{i j}\right\}_{i, j=1,2}$ be the solution of the static Riccati equation:

$$
\mathbf{o}=\left(\mathbf{a}_{z} \mathbf{o} \mathbf{a}_{z}^{T}+\boldsymbol{\Sigma}_{z z}\right)-\mathbf{k a}_{s}\left(\mathbf{a}_{z} \mathbf{o} \mathbf{a}_{z}^{T}+\boldsymbol{\Sigma}_{z z}\right),
$$

where

$$
\mathbf{k}=\left(\mathbf{a}_{z} \mathbf{o} \mathbf{a}_{z}^{T}+\boldsymbol{\Sigma}_{z z}\right) \mathbf{a}_{s}^{T}\left[\mathbf{a}_{s}\left(\mathbf{a}_{z} \mathbf{o a _ { z } ^ { T }}+\boldsymbol{\Sigma}_{z z}\right) \mathbf{a}_{s}^{T}+\boldsymbol{\Sigma}_{s s}\right]^{-1} .
$$

The steady-state filters are then given by the filtering equation

$$
\hat{\mathbf{z}}_{t}=\mathbf{a}_{z} \hat{\mathbf{z}}_{t-1}+\mathbf{k}\left(\mathbf{s}_{t}-\mathbf{a}_{s} \mathbf{a}_{z} \hat{\mathbf{z}}_{t-1}\right) .
$$

Define $\boldsymbol{\delta}_{t} \equiv \hat{\mathbf{z}}_{t}-\mathbf{z}_{t}$, which is the difference between the uninformed investors' estimates of $\mathbf{z}_{t}$ and its true values. Equation (A6) yields

$$
\boldsymbol{\delta}_{t}=\mathbf{a}_{\delta} \boldsymbol{\delta}_{t-1}+\mathbf{b}_{\delta} \boldsymbol{\epsilon}_{t},
$$

where $\mathbf{a}_{\delta}=\mathbf{a}_{z}-\mathbf{k} \mathbf{a}_{s} \mathbf{a}_{z}$ and $\mathbf{b}_{\delta}=\mathbf{k}\left(\mathbf{a}_{s} \mathbf{b}_{z}+\mathbf{b}_{s}\right)-\mathbf{b}_{z}$. In particular, for $\Theta \equiv$ $\hat{F}_{t}-F_{t}$,

$$
\Theta_{t}=a_{\Theta} \Theta_{t-1}+\mathbf{b}_{\Theta} \boldsymbol{\epsilon}_{t}
$$

${ }^{24}$ Under the assumption that the prior distribution is normal and $\left|a_{F}\right| \leq 1,\left|a_{Z}\right|<$ 1 , the convergence of the filters to their steady-state solution is guaranteed (see, e.g., Anderson and Moore 1979). 
where $a_{\Theta}$ is the first diagonal element of $\mathbf{a}_{\delta}$ and $\mathbf{b}_{\Theta}$ is the first row vector of $\mathbf{b}_{\delta}$.

Since in the current model all the processes are linear in the underlying shocks and all the shocks are normal, all the variables defined above are jointly normal. We can easily calculate the conditional and unconditional variances and covariances of any variables. Let $y_{i, t}, i=1,2$, be any two random variables such that $y_{i, t}=a_{i} y_{i, t-1}+\mathbf{b}_{i} \epsilon_{t}$ and $\left|a_{i}\right|<1$. Then

$$
\boldsymbol{\kappa}_{y_{i}, y_{j}} \equiv \operatorname{cov}\left(y_{i, t}, y_{j, t}\right)=\frac{1}{1-a_{i} a_{j}} \mathbf{b}_{i} \mathbf{\Sigma} \mathbf{b}_{j}^{T}, \quad i, j=1,2 .
$$

\section{B. Theorems 2 and 3}

Given the form of the price function and the solution to the uninformed investors' expectations, we can derive the process of excess stock returns:

$$
Q_{t+1} \equiv P_{t+1}+D_{t+1}-R P_{t}=e_{0}+e_{Z} Z_{t}-e_{\Theta} \Theta_{t}+\mathbf{b}_{Q} \boldsymbol{\epsilon}_{t+1},
$$

where $e_{0}=r p_{0}, e_{Z}=\left(R-a_{Z}\right) p_{Z}, e_{\Theta}=\left(R-a_{\Theta}\right)\left(a-p_{F}\right)$, and $\mathbf{b}_{Q}=(1+$ $a) \mathbf{b}_{F}+\mathbf{b}_{D}-p_{Z} \mathbf{b}_{Z}+\left(a-p_{F}\right) \mathbf{b}_{\Theta}$. The expected excess returns for the informed and the uninformed investors are

$$
E_{t}^{i}\left[Q_{t+1}\right]=e_{0}+e_{Z} Z_{t}-e_{\Theta} \Theta_{t}, \quad E_{t}^{u}\left[Q_{t+1}\right]=e_{0}+e_{Z} \hat{Z}_{t} .
$$

Note that the expected returns are linear in the state variables: $Z_{t}$ and $\Theta_{t}$ for the informed investors and $\hat{Z}_{t}$ for the uninformed investors. Let $\boldsymbol{\Psi}_{t}^{i}=\left(1, Z_{t}\right.$, $\left.\Theta_{t}\right)^{\top}$ and $\boldsymbol{\Psi}_{t}^{u}=\left(1, \hat{Z}_{t}\right)^{\top}$ be the vectors of state variables for the informed and the uninformed investors, respectively. The vector $\boldsymbol{\Psi}_{t}^{k}(k=i, u)$ follows an $\mathrm{AR}(1)$ process:

$$
\boldsymbol{\Psi}_{t}^{k}=\mathbf{a}_{\Psi}^{k} \boldsymbol{\Psi}_{t-1}^{k}+\mathbf{b}_{\Psi}^{k} \boldsymbol{\epsilon}_{t}^{k},
$$

where $\boldsymbol{\epsilon}_{t}^{i}=\boldsymbol{\epsilon}_{t}$ and $\boldsymbol{\epsilon}_{t}^{u}=\left(\Theta_{t-1}, \boldsymbol{\epsilon}_{t}\right) ; \mathbf{a}_{\Psi}^{k}$ and $\mathbf{b}_{\Psi}^{k}(k=i, u)$ can be easily calculated from equation (A6).

Let $2_{t+1}^{i}=\left(Q_{t+1}, q_{t+1}\right)^{T}$ be the vector of excess returns for the informed investors and $2_{t+1}^{u}=Q_{t+1}$ the vector for the uninformed investors. Then

$$
2_{t+1}^{k}=\mathbf{e}_{2}^{k} \Psi_{t}^{k}+\mathbf{b}_{2}^{k} \boldsymbol{\epsilon}_{t+1}^{k}, \quad k=i, u,
$$

where

$$
\mathbf{e}_{2}^{i}=\left(\begin{array}{ccc}
e_{0} & e_{Z} & e_{\Theta} \\
0 & 1 & 0
\end{array}\right), \quad \mathbf{b}_{2}^{i}=\left(\begin{array}{l}
\mathbf{b}_{Q} \\
\mathbf{b}_{q}
\end{array}\right),
$$

$\mathbf{e}_{2}^{u}=\left(e_{0}, e_{Z}\right)$, and $\mathbf{b}_{2}^{u}=\left(-e_{\Theta}-\left(p_{F} e_{Z} / p_{Z}\right), \mathbf{b}_{Q}\right)$. Furthermore, let $\mathbf{X}_{t}^{k}$ be the vector of investors' holdings of risky assets: $\mathbf{X}_{t}^{i}=\left(X_{t}^{i}, y_{t}\right)^{\top}$ and $\mathbf{X}_{t}^{u}=X_{t}^{u}$.

With this notation, both the informed and the uninformed investors' optimization problem can be expressed in the form of the Bellman equation: ${ }^{25}$

${ }^{25}$ The transversality condition we impose is $\lim _{s \rightarrow \infty} E_{t}\left[J\left(W_{t+s} ; \Psi_{t+s} ; t+s\right)\right]=0$, which is of the Merton type (see Merton 1969). 


$$
\begin{gathered}
0=\max _{\mathbf{X}, c}\left\{-\beta^{t} e^{-\gamma c_{t}}+E\left[J\left(W_{t+1} ; \boldsymbol{\Psi}_{t+1}\right) \mid \mathcal{O}_{t}\right]-J\left(W_{t} ; \boldsymbol{\Psi}_{t} ; t\right)\right\} \\
\text { subject to } W_{t+1}=\left(W_{t}-c_{t}\right) R+\mathbf{X}_{t}^{\top} \boldsymbol{2}_{t+1} .
\end{gathered}
$$

Here the superscript $k=i$, $u$ has been dropped to simplify notation. Consider the following trial solution for the value function:

$$
J\left(W_{t} ; \boldsymbol{\Psi}_{t} ; t\right)=-\beta^{t} e^{-\alpha W_{t}-1 / 2 \Psi_{t}^{T} \mathbf{v} \Psi_{t}},
$$

where $\mathbf{v}$ is an $n \times n$ symmetric matrix of constants $(n=3$ if $k=i$ and $n=$ 2 if $k=u)$. Define $\mathbf{v}_{a a}=\mathbf{a}_{\Psi}^{\top} \mathbf{v} \mathbf{a}_{\Psi}, \mathbf{v}_{b b}=\mathbf{b}_{\Psi}^{\top} \mathbf{v} \mathbf{b}_{\Psi}, \mathbf{v}_{a b}=\mathbf{a}_{\Psi}^{\top} \mathbf{v} \mathbf{b}_{\Psi}, \boldsymbol{\Omega}=\left(\boldsymbol{\Sigma}^{-1}+\right.$ $\left.\mathbf{v}_{b b}\right)^{-1}, \boldsymbol{\Gamma}=\left(\mathbf{b}_{2} \boldsymbol{\Omega} \mathbf{b}_{2}^{\top}\right)^{-1}, \mathbf{g}=\mathbf{e}_{2}-\mathbf{b}_{2} \boldsymbol{\Omega} \mathbf{v}_{a b}^{\top}$. Also define $d=\left|\boldsymbol{\Omega}^{-1} \boldsymbol{\Sigma}\right|^{-1 / 2}$. It is straightforward to show that

$$
\begin{aligned}
E\left[J_{t+1} \mid \rho_{t}\right]= & -d \beta^{t+1} \exp \left[-\alpha R\left(W_{t}-c_{t}\right)-\alpha \boldsymbol{\Psi}_{t}^{T} \mathbf{g}^{T} \mathbf{X}_{t}\right. \\
& \left.+1 / 2 \alpha^{2} \mathbf{X}_{t}^{T} \boldsymbol{\Gamma}^{-1} \mathbf{X}_{t}-1 / 2 \Psi_{t}^{T}\left(\mathbf{v}_{a a}-\mathbf{v}_{a b} \mathbf{\Omega} \mathbf{v}_{a b}^{T}\right) \boldsymbol{\Psi}_{t}\right] .
\end{aligned}
$$

The first-order condition for the optimal investment-consumption policy is

$$
\begin{gathered}
\mathbf{x}_{t}=\frac{1}{\alpha} \mathbf{f}_{2} \Psi_{t}, \quad \mathbf{f}_{2} \equiv \boldsymbol{\Gamma}\left(\mathbf{e}_{2}-\mathbf{b}_{2} \mathbf{\Omega} \mathbf{v}_{a b}^{T}\right), \\
c_{t}=\bar{c}+\frac{\alpha R}{\gamma+\alpha R} W_{t}+\frac{1}{2(\gamma+\alpha R)} \Psi_{t}^{T} \mathbf{m} \Psi_{t}, \quad \mathbf{m}=\mathbf{v}_{a a}-\mathbf{v}_{a b} \boldsymbol{\Omega} \mathbf{v}_{a b}^{T}+\mathbf{g}^{T} \boldsymbol{\Gamma} \mathbf{g},
\end{gathered}
$$

and

$$
\bar{c}=\frac{1}{\gamma+\alpha R} \ln \left(\frac{\gamma}{\alpha \beta R d}\right) .
$$

Substituting the optimal consumption-investment policy back into the Bellman equation, we obtain

$$
\begin{gathered}
\alpha=\frac{r \gamma}{R}, \quad \bar{c}=-\frac{1}{\gamma R} \ln (r \beta d) \\
\exp \left\{-1 / 2 \boldsymbol{\Psi}_{t}^{T}\left[\frac{1}{R} \mathbf{m}-\mathbf{v}+\left(\gamma \bar{c}+\ln \frac{r}{R}\right) \mathbf{i}_{11}\right] \boldsymbol{\Psi}_{t}\right\}=1
\end{gathered}
$$

Here, $\mathbf{i}_{11}^{(n, n)}$ is an $n \times n$ index matrix. ${ }^{26}$ This leads to the following equation for $\mathbf{v}:{ }^{27}$

$$
\frac{1}{1+r} \mathbf{m}-\mathbf{v}+\left[\gamma \bar{c}+\ln \left(\frac{r}{1+r}\right)\right] \mathbf{i}_{11}=0 .
$$

${ }^{26}$ An index matrix $\mathbf{i}_{i j}^{(m, n)}$ is an $m \times n$ matrix with the element $\{i, j\}$ being one and all other elements being zero. For example,

$$
\mathbf{i}_{11}^{(2,2)}=\left(\begin{array}{ll}
1 & 0 \\
0 & 0
\end{array}\right)
$$

${ }^{27}$ In the case of the informed investors-e.g., $\mathbf{v}, \mathbf{m}$, and $\mathbf{i}_{11}^{(3,3)}$ are all symmetric $3 \times$ 3 matrices-eq. (A18) gives a set of six polynomial equations that can be solved for $\mathbf{v}$. 
The solution to this set of equations determines $\mathbf{v}$, which in turn fully determines the value function and the optimal investment-consumption policies. ${ }^{28}$ From equation (A15), we can rewrite the investors' optimal portfolios as

$$
\mathbf{X}_{t}=\frac{1}{\alpha} \Gamma E\left[\boldsymbol{2}_{t+1} \mid \rho_{t}\right]-\frac{1}{\alpha} \mathbf{h} \Psi_{t}, \quad \mathbf{h}=\Gamma \mathbf{b}_{2} \boldsymbol{\Omega} \mathbf{v}_{a b}^{T} .
$$

\section{Proposition 1}

From theorems 1-3, we can now prove proposition 1. Express investors' optimal stockholdings as

$$
X_{t}^{i}=f_{0}^{i}+f_{Z}^{i} Z_{t}+f_{\Theta}^{i} \Theta_{t}, \quad X_{t}^{u}=f_{0}^{u}+f_{Z}^{u} \hat{Z}_{t} .
$$

In order for the conjectured price function to be an equilibrium, the stock market has to clear. From equation (A20),

$$
1=\omega X_{t}^{i}+(1-\omega) X_{t}^{u}=\omega\left(f_{0}^{i}+f_{Z}^{i} Z_{t}+f_{\Theta}^{i} \Theta_{t}\right)+(1-\omega)\left(f_{0}^{u}+f_{Z}^{u} \hat{Z}_{t}\right) .
$$

Since $\hat{Z}_{t}=Z_{t}-\left(p_{F} / p_{Z}\right) \Theta_{t}$, where $\mu=p_{Z} / p_{F}$, equation (A21) holds if the following is true:

$$
\omega f_{0}^{i}+(1-\omega) f_{0}^{u}=1, \quad \omega f_{Z}^{i}+(1-\omega) f_{Z}^{u}=0, \quad \omega f_{\Theta}^{i}+(1-\omega) \frac{p_{F}}{p_{Z}} f_{Z}^{u}=0 .
$$

Equation (A22) is a set of algebraic equations. Its solution determines $p_{0}, p_{F}$, and $p_{Z}$, which completely specify the proposed equilibrium price function. We are not able to express the roots of equation (A22) in analytical form. A numerical method can be used to solve equation (A22). This completes the proof of proposition 1 .

\section{Appendix B}

\section{Some Conditional and Unconditional Moments}

In this Appendix, I derive the results used in the theorems in Sections IV-VI. Most of these results involve the calculation of some conditional and unconditional moments.

\section{A. Moments of Volume and Its Correlation} with Changes in Prices and Dividends

Let $\mathbf{y}^{\prime}=\left(y_{1}, y_{2}\right)$ be a two-dimensional random variable and $\mathbf{y} \sim N\left(0, \boldsymbol{\Sigma}_{y}\right)$. Suppose

$$
\boldsymbol{\Sigma}_{y}=\left(\begin{array}{ll}
\sigma_{1}^{2} & \sigma_{12} \\
\sigma_{12} & \sigma_{2}^{2}
\end{array}\right),
$$

${ }^{28}$ The imposed transversality condition is satisfied by the solution. It is easy to show that $E_{t}\left[J_{t+1}\right]=R^{-1} J_{t}$. Hence, $E_{t}\left[J_{t+\tau}\right]=R^{-\tau} J_{t}$ and $\lim _{\tau \rightarrow \infty} E_{t}\left[J_{t+\tau}\right]=0$ since $R>1$ as assumed, which is the Merton transversality condition. 
where $\sigma_{12}=\rho_{12} \sigma_{1} \sigma_{2}$. It is easy to show that

$$
E\left[\left|y_{1}\right|\right]=\frac{1}{\sqrt{2 \pi \sigma_{1}}} \int_{-\infty}^{+\infty}\left|y_{1}\right| e^{-y_{1}^{2} / 2 \sigma_{1}^{2}} d y_{1}=\sqrt{\frac{2}{\pi}} \sigma_{1}
$$

and

$$
\begin{aligned}
\rho_{\left|y_{1}\right|,\left|y_{2}\right|}= & \frac{1}{\sigma_{1} \sigma_{2}}\left[E\left[\left|y_{1} y_{2}\right|\right]-E\left[\left|y_{1}\right|\right] E\left[\left|y_{2}\right|\right]\right] \\
= & \frac{1}{2 \pi \sqrt{1-\rho_{12}^{2}}} \\
& \times \int_{-\infty}^{+\infty} \int_{-\infty}^{+\infty}\left|y_{1}^{\prime} y_{2}^{\prime}\right| \exp \left[-\frac{y_{1}^{\prime 2}+y_{2}^{\prime 2}+2 \rho_{12} y_{1}^{\prime} y_{2}^{\prime}}{2\left(1-\rho_{12}^{2}\right)}\right] d y_{1}^{\prime} d y_{2}^{\prime}-\frac{2}{\pi} \\
= & \left(1-\frac{2}{\pi}\right)\left(1-\sqrt{1-\rho_{12}^{2}}\right),
\end{aligned}
$$

where $y_{1}^{\prime}=y_{1} / \sigma_{1}$ and $y_{2}^{\prime}=y_{2} / \sigma_{2}$.

The trading volume $V_{t}=(1-\omega)\left|f_{Z}^{u}\right|\left|\delta \hat{Z}_{t}\right|$. From the result above,

$$
\bar{V} \equiv E\left[V_{t}\right]=(1-\omega)\left|f_{Z}^{u}\right| \sqrt{\frac{2}{\pi}} \sigma_{\delta \hat{L}}, \quad \operatorname{var}\left(V_{t}\right)=(\pi-1 / 2) \bar{V}^{2} .
$$

From equation (B2),

$$
\rho_{V_{t},\left|\delta Y_{t}\right|}=\left(1-\frac{2}{\pi}\right)\left(1-\sqrt{1-\rho_{\delta Y_{t}, \delta \hat{t}_{t}}^{2}}\right), \quad Y_{t}=P_{t}, D_{t} .
$$

The correlation coefficient, $\rho_{\delta P_{t}, \delta \hat{z}_{t}}$, and $\rho_{\delta D_{t}, \delta \hat{z}_{t}}$ can be calculated from Appen$\operatorname{dix}$ A.

\section{B. Expected Future Excess Returns Conditional on Current Return and Volume}

Let us first consider the expectations conditional on the absolute value of other variables in the case of a jointly normal distribution. Then we can apply it to the problem of expected future excess returns conditional on past returns and volume.

Let $\mathbf{y}=\left(\mathbf{y}_{a}^{T}, \mathbf{y}_{b}^{T}\right)^{T}$. Suppose $\mathbf{y} \sim N\left(0, \mathbf{\Sigma}_{y}\right)$, where $\boldsymbol{\Sigma}_{y}$ is the covariance matrix. Rewrite $\boldsymbol{\Sigma}_{y}$ as

$$
\boldsymbol{\Sigma}_{y}=\left(\begin{array}{ll}
\boldsymbol{\Sigma}_{a a} & \mathbf{\Sigma}_{a b} \\
\boldsymbol{\Sigma}_{b a} & \mathbf{\Sigma}_{b b}
\end{array}\right)
$$

It is known that

$$
E\left[\mathbf{y}_{a} \mid \mathbf{y}_{b}\right]=\boldsymbol{\Sigma}_{a b} \boldsymbol{\Sigma}_{b b}^{-1} \mathbf{y}_{b}
$$


Let us first consider a simple case. Let $\mathbf{y}_{a}=y_{1}$ and $\mathbf{y}_{b}^{T}=\left(y_{2}, y_{3}\right)$. We want to calculate the conditional expectation: $E\left[y_{1}\left|y_{2}=l_{2},\right| y_{3} \mid=l_{3}\right]$. Define $f\left(\mathbf{y}_{b}\right)$ $=e^{-1 / 2 \mathbf{y}_{b}^{\top} \boldsymbol{\Sigma}_{b b}^{-1} \mathbf{y}_{b}}$. Let $\mathbf{l}_{b}^{\prime}=\left(l_{2}, l_{3}\right)$. It is easy to show that

$$
\begin{aligned}
E\left[y_{1}\left|y_{2}=l_{2},\right| y_{3} \mid=l_{3}\right] & =\boldsymbol{\Sigma}_{a b} \boldsymbol{\Sigma}_{b b}^{-1}\left\{\mathbf{I}_{11}+\frac{f\left\{\left[\mathbf{i}_{11}^{(2,2)}+\mathbf{i}_{22}^{(2,2)}\right] \mathbf{l}_{b}\right\}-f\left\{\left[\mathbf{i}_{11}^{(2,2)}-\mathbf{i}_{22}^{(2,2)}\right] \mathbf{l}_{b}\right\}}{f\left\{\left[\mathbf{i}_{11}^{(2,2)}+\mathbf{i}_{22}^{(2,2)}\right] \mathbf{l}_{b}\right\}+f\left\{\left[\mathbf{i}_{11}^{(2,2)}-\mathbf{i}_{22}^{(2,2)}\right] \mathbf{l}_{b}\right\}} \mathbf{i}_{22}^{(2,2)}\right\} \mathbf{l}_{b} \\
& =\boldsymbol{\Sigma}_{a b} \boldsymbol{\Sigma}_{b b}^{-1}\left\{\mathbf{i}_{11}^{(2,2)}-\tanh \left[\mathbf{l}_{b}^{T} \mathbf{i}_{11}^{(2,2)} \mathbf{\Sigma}_{b b}^{-1} \mathbf{i}_{22}^{(2,2)} \mathbf{l}_{b}\right] \mathbf{i}_{22}^{(2,2)}\right\} \mathbf{l}_{b},
\end{aligned}
$$

where $\mathbf{i}_{i j}^{(m, n)}$ is the index matrix.

Now suppose that $\mathbf{y}_{b}^{T}=\left(y_{2}, y_{3}, y_{4}, y_{5}\right)$. We want to calculate the following conditional expectation: $E\left[y_{1}\left|y_{2}=l_{2},\right| y_{3}\left|=l_{3}, y_{4}=l_{4},\right| y_{5} \mid=l_{5}\right]$. Let $\mathbf{l}_{b}^{T}=$ $\left(l_{2}, l_{3}, l_{4}, l_{5}\right)$ and

$$
\begin{aligned}
& g_{24}=\mathbf{l}_{b}^{T} \mathbf{i}_{22}^{(4,4)} \boldsymbol{\Sigma}_{b b}^{-1} \mathbf{i}_{44}^{(4,4)} \mathbf{1}_{b}, \\
& g_{2 o}=\mathbf{l}_{b}^{T} \mathbf{i}_{22}^{(4,4)} \boldsymbol{\Sigma}_{b b}^{-1}\left[\mathbf{i}_{11}^{(4,4)}+\mathbf{i}_{33}^{(4,4)}\right] \mathbf{l}_{b}, \\
& g_{4 o}=\mathbf{l}_{b}^{T} \mathbf{i}_{44}^{(4,4)} \boldsymbol{\Sigma}_{b b}^{-1}\left[\mathbf{i}_{11}^{(4,4)}+\mathbf{i}_{33}^{(4,4)}\right] \mathbf{l}_{b} .
\end{aligned}
$$

It can be shown that

$$
\begin{gathered}
E\left[y_{1}\left|y_{2}=l_{2},\right| y_{3}\left|=l_{3}, y_{4}=l_{4},\right| y_{5} \mid=l_{5}\right] \\
=\boldsymbol{\Sigma}_{a b} \mathbf{\Sigma}_{b b}^{-1}\left[\mathbf{i}_{11}^{(4,4)}+\mathbf{i}_{33}^{(4,4)}+\eta_{2}\left(\mathbf{l}_{b}\right) \mathbf{i}_{22}^{(4,4)}+\eta_{4}\left(\mathbf{l}_{b}\right) \mathbf{i}_{44}^{(4,4)}\right] \mathbf{l}_{b},
\end{gathered}
$$

where

$$
\begin{aligned}
& \eta_{2}\left(\mathbf{l}_{b}\right)=\frac{\cosh \left(g_{24}\right) \sinh \left(g_{2 o}\right) \cosh \left(g_{4 o}\right)+\sinh \left(g_{24}\right) \cosh \left(g_{2 o}\right) \sinh \left(g_{4 o}\right)}{\cosh \left(g_{24}\right) \cosh \left(g_{2 o}\right) \cosh \left(g_{4 o}\right)+\sinh \left(g_{24}\right) \sinh \left(g_{2 o}\right) \sinh \left(g_{4 o}\right)} \\
& \eta_{4}\left(\mathbf{l}_{b}\right)=\frac{\cosh \left(g_{24}\right) \cosh \left(g_{2 o}\right) \sinh \left(g_{4 o}\right)+\sinh \left(g_{24}\right) \sinh \left(g_{2 o}\right) \cosh \left(g_{4 o}\right)}{\cosh \left(g_{24}\right) \cosh \left(g_{2 o}\right) \cosh \left(g_{4 o}\right)+\sinh \left(g_{24}\right) \sinh \left(g_{2 o}\right) \sinh \left(g_{4 o}\right)} .
\end{aligned}
$$

Expand $\eta_{2}$ and $\eta_{4}$ in terms of $\mathbf{l}_{b}$ and keep only the lowest-order terms, which are quadratic in $\mathbf{l}_{b}$. Then $\eta_{2}\left(\mathbf{l}_{b}\right)=g_{2 o}+o^{2}\left(\mathbf{l}_{b}\right)$ and $\eta_{4}\left(\mathbf{l}_{b}\right)=g_{4 o}+o^{2}\left(\mathbf{l}_{b}\right)$, where $o^{2}(\cdot)$ denotes the terms of the higher order of $l_{b}^{2}$. Under the quadratic approximation, we have

$$
\begin{gathered}
E\left[y_{1}\left|y_{2}=l_{2},\right| y_{3}\left|=l_{3}, y_{4}=l_{4},\right| y_{5} \mid=l_{5}\right] \\
=\mathbf{\Sigma}_{a b} \mathbf{\Sigma}_{b b}^{-1}\left[\mathbf{i}_{11}^{(4,4)}+\mathbf{i}_{33}^{(4,4)}+g_{2 o}\left(\mathbf{l}_{b}\right) \mathbf{i}_{22}^{(4,4)}+g_{4 o}\left(\mathbf{l}_{b}\right) \mathbf{i}_{44}^{(4,4)}\right] \mathbf{l}_{b} .
\end{gathered}
$$

Given the results above, we can calculate the conditional expectation $E\left[\tilde{Q}_{t+1} \mid \tilde{Q}_{t}, V_{t}\right]$. Since $V_{t}=\left|(1-\omega) f_{Z}^{u} \delta \hat{Z}_{t}\right|, E\left[\tilde{Q}_{t+1} \mid \tilde{Q}_{t}, V_{t}\right]=E\left[\tilde{Q}_{t+1} \mid \tilde{Q}_{t}\right.$, $\left.\left|\delta \hat{Z}_{t}\right|\right]$. From Appendix A, we know that $Q_{t+1}, Q_{t}$, and $\delta \hat{Z}_{t}$ are jointly normal. Using equation (B6) and letting $\left(\mathbf{l}_{b}\right)^{T}=\left(Q_{t}, \delta \hat{Z}_{t}\right)$, we get

$$
E\left[\tilde{Q}_{t+1}\left|\tilde{Q}_{t},\right| \delta \hat{Z}_{t} \mid\right]=\boldsymbol{\Sigma}_{a b} \boldsymbol{\Sigma}_{b b}^{-1}\left\{\mathbf{i}_{11}^{(2,2)}-\tanh \left[\mathbf{l}_{b}^{T} \mathbf{i}_{11}^{(2,2)} \boldsymbol{\Sigma}_{b b}^{-1} \mathbf{i}_{22}^{(2,2)} \mathbf{l}_{b}\right] \mathbf{i}_{22}^{(2,2)}\right\} \mathbf{l}_{b} .
$$


Let

$$
\begin{aligned}
& \mathbf{h} \equiv\left(\begin{array}{cc}
h_{Q, Q} & h_{Q, \delta \hat{z}} \\
h_{\delta \hat{z}, Q} & h_{\delta \hat{z}, \delta \hat{z}}
\end{array}\right)=\mathbf{\Sigma}_{b b}^{-1}=\left(\begin{array}{cc}
\kappa_{Q_{t}, Q_{t}} & \kappa_{Q_{t}, \delta z_{t}} \\
\boldsymbol{\kappa}_{Q_{t}, \delta \hat{z}_{t}} & \kappa_{\delta \hat{z}_{t}, \delta \hat{Z}_{t}}
\end{array}\right)^{-1}, \\
& \boldsymbol{\lambda} \equiv\left(\lambda_{Q} \lambda_{\delta \hat{z}}\right)=\boldsymbol{\Sigma}_{a b} \boldsymbol{\Sigma}_{b b}^{-1}=\left(\begin{array}{c}
\kappa_{Q_{t+1}, Q_{t}} h_{Q, Q}+\kappa_{Q_{t+1}, \delta \hat{z}_{t}} h_{Q, \delta \hat{z}} \\
\kappa_{Q_{t+1}, Q_{t}} h_{Q, \delta \hat{Z}}+\kappa_{Q_{t+1}, \delta \hat{z}_{t}} h_{\delta \hat{z}, \delta \hat{z}}
\end{array}\right)^{\top} .
\end{aligned}
$$

Let $\lambda_{V}=\lambda_{\delta \hat{Z}} /\left[(1-\omega)\left|f_{Z}^{u}\right|\right]$ and $h_{Q}=h_{Q \delta \tilde{Z}} /\left[(1-\omega)\left|f_{Z}^{u}\right|\right]$. Then

$$
E\left[\tilde{Q}_{t+1} \mid \tilde{Q}_{t}, V_{t}\right]=\lambda_{Q} \tilde{Q}_{t}-\lambda_{V} \tanh \left(h_{Q} V_{t} \tilde{Q}_{t}\right) V_{t} .
$$

\section{Theorem 8}

In the case of symmetric information (i.e., $\sigma_{S}^{2}=0$ ), $\delta \hat{Z}_{t}=\delta Z_{t}$. It is easy to show that

$$
\begin{aligned}
\kappa_{Q_{t}, Q_{t}}^{(0)} & =\mathbf{b}_{D} \Sigma \mathbf{b}_{D}^{T}+(1+a)^{2} \mathbf{b}_{F} \Sigma \mathbf{b}_{F}^{T}+\frac{p_{Z}^{2}}{1-a_{Z}^{2}}\left[1+R\left(R-2 a_{Z}\right)\right] \mathbf{b}_{Z} \boldsymbol{\Sigma} \mathbf{b}_{Z}^{T}, \\
\kappa_{\delta Z_{t}, \delta Z_{t}}^{(0)} & =\frac{2}{1+a_{Z}} \mathbf{b}_{Z} \boldsymbol{\Sigma} \mathbf{b}_{Z}^{T}, \quad \kappa_{Q_{t}, \delta Z_{t}}^{(0)}=-\frac{(1+R) p_{Z}}{1+a_{Z}} \mathbf{b}_{Z} \boldsymbol{\Sigma} \mathbf{b}_{Z}^{T}, \\
\kappa_{Q_{t+1}, Q_{t}}^{(0)} & =\frac{e_{Z} p_{Z}}{1-a_{Z}^{2}}\left(1-a_{Z} R\right) \mathbf{b}_{Z} \Sigma \mathbf{b}_{Z}^{T}, \quad \kappa_{Q_{t+1}, \delta Z_{t}}^{(0)}=\frac{e_{Z}}{1+a_{Z}} \mathbf{b}_{Z} \boldsymbol{\Sigma} \mathbf{b}_{Z}^{T} .
\end{aligned}
$$

Here, the superscript (0) denotes the case $\sigma_{S}=0$. Then

$$
\begin{aligned}
\lambda_{Q}^{(0)} & =\left|\mathbf{h}^{(0)}\right| \frac{a_{Z} e_{Z} p_{Z} r}{\left(1-a_{Z}^{2}\right)\left(1+a_{Z}\right)}\left(\mathbf{b}_{Z} \mathbf{\Sigma} \mathbf{b}_{Z}^{T}\right)^{2}, \\
\lambda_{\delta Z}^{(0)} & =\left|\mathbf{h}^{(0)}\right| \frac{e_{Z}}{1+a_{Z}}\left\{\left[\mathbf{b}_{D} \mathbf{\Sigma} \mathbf{b}_{D}^{T}+(1+a)^{2} \mathbf{b}_{F} \mathbf{\Sigma} \mathbf{b}_{F}^{T}\right]+\frac{\left(r+a_{F}\right) R}{1-a_{Z}^{2}} \mathbf{b}_{Z} \mathbf{\Sigma} \mathbf{b}_{Z}^{T}\right\} \mathbf{b}_{Z} \mathbf{\Sigma} \mathbf{b}_{Z}^{T} .
\end{aligned}
$$

Since $\left|\mathbf{h}^{(0)}\right|$ is positive,

$$
\lambda_{Q V}^{(0)} \propto h_{Q \delta Z}^{(0)} \lambda_{\delta Z}^{(0)}=\left|\mathbf{h}^{(0)}\right|\left[-\kappa_{Q t, \delta Z_{t}}^{(0)}\right] \lambda_{\delta Z}^{(0)}>0 .
$$

This proves theorem 8 .

D. Deriving Equation (32)

Using equation (B8), we can calculate $E\left[\tilde{Q}_{t+1} \mid \tilde{Q}_{t}, V_{t} ; \tilde{Q}_{t-1}, V_{t-1}\right]$. Let

$$
\mathbf{1}_{b}^{T}=\left(\tilde{Q}_{t}, \delta \hat{Z}_{t}, \tilde{Q}_{t-1}, \delta \hat{Z}_{t-1}\right) \text {. }
$$

Then

$$
\begin{aligned}
& g_{2 o}=\left(\boldsymbol{\Sigma}_{b b}^{-1}\right)_{21}\left|\delta \hat{Z}_{t}\right| \tilde{Q}_{t}+\left(\mathbf{\Sigma}_{b b}^{-1}\right)_{23}\left|\delta \hat{Z}_{t}\right| \tilde{Q}_{t-1}, \\
& g_{4 o}=\left(\mathbf{\Sigma}_{b b}^{-1}\right)_{41}\left|\delta \hat{Z}_{t-1}\right| \tilde{Q}_{t}+\left(\mathbf{\Sigma}_{b b}^{-1}\right)_{43}\left|\delta \hat{Z}_{t-1}\right| \tilde{Q}_{t-1} .
\end{aligned}
$$


Substituting into equation (B8), we obtain equation (32). Here, I have omitted the detailed derivations of the coefficients, which are straightforward.

\section{References}

Admati, Anat R., and Pfleiderer, Paul. "A Monopolistic Market for Innovations." J. Econ. Theory 39 (August 1986): 400-438.

- "A Theory of Intraday Patterns: Volume and Price Variability." Rev. Financial Studies 1, no. 1 (1988): 3-40.

- "Direct and Indirect Sale of Information." Econometrica 58 (July 1990): 901-28.

Anderson, Brian D. O., and Moore, John B. Optimal Filtering. Englewood Cliffs, N.J.: Prentice-Hall, 1979.

Bamber, Linda Smith. "The Information Content of Annual Earnings Releases: A Trading Volume Approach.” J. Accounting Res. 24 (Spring 1986): 40-56.

Beaver, William H. "The Information Content of Annual Earnings Announcements." J. Accounting Res. 6 (suppl., 1968): 67-92.

Campbell, John Y.; Grossman, Sanford J.; and Wang, Jiang. "Trading Volume and Serial Correlation in Stock Returns." Q.J.E. (1993), in press.

Campbell, John Y., and Kyle, Albert S. "Smart Money, Noise Trading and Stock Price Behavior." Rev. Econ. Studies 60 (January 1993): 1-34.

Constantinides, George M. "Intertemporal Asset Pricing with Heterogeneous Consumers and without Demand Aggregation.” J. Bus. 55 (April 1982): 253-67.

- "Theory of Valuation: Overview and Recent Developments." In Theory of Valuation: Frontiers of Modern Financial Theory, edited by Sudipto Bhattacharya and George M. Constantinides. Totowa, N.J.: Rowman and Littlefield, 1989.

Copeland, Thomas E. "A Model of Asset Trading under the Assumption of Sequential Information Arrival.” J. Finance 31 (September 1976): 1149-68.

Detemple, Jérôme B. "Asset Pricing in a Production Economy with Incomplete Information." J. Finance 41 (June 1986): 383-91.

Dothan, Michael U., and Feldman, David. "Equilibrium Interest Rates and Multiperiod Bonds in a Partially Observable Economy." J. Finance 41 (June 1986): 369-82.

Dumas, B. "Two-Person Dynamic Equilibrium in the Capital Market." Rev. Financial Studies 2, no. 2 (1989): 157-88.

Fleming, Wendell H., and Rishel, Raymond W. Deterministic and Stochastic Optimal Control. New York: Springer-Verlag, 1975.

Foster, F. D., and Viswanathan, S. "A Theory of the Interday Variations in Volume, Variance, and Trading Costs in Securities Markets." Rev. Financial Studies 3, no. 4 (1990): 593-624.

- "The Effect of Public Information and Competition on Trading Volume and Price Volatility." Rev. Financial Studies 6, no. 1 (1993): 23-56.

Gallant, A. Ronald; Rossi, Peter E.; and Tauchen, George. "Stock Prices and Volume." Rev. Financial Studies 5, no. 2 (1992): 199-242.

Gennotte, Gerard. "Optimal Portfolio Choice under Incomplete Information.” J. Finance 41 (July 1986): 733-46.

Green, Jerry R. "Informational Efficiency and Equilibrium." Discussion Paper no. 284. Cambridge, Mass.: Harvard Univ., Inst. Econ. Res., 1973. 
Grossman, Sanford J. "On the Efficiency of Competitive Stock Markets Where Traders Have Diverse Information." J. Finance 31 (May 1976): 573-85.

Grossman, Sanford J., and Stiglitz, Joseph E. "On the Impossibility of Informationally Efficient Markets.” A.E.R. 70 (June 1980): 393-408.

Grundy, Bruce D., and McNichols, Maureen. "Trade and the Revelation of Information through Prices and Direct Disclosure." Rev. Financial Studies 2, no. 4 (1989): 495-526.

Harris, Milton, and Raviv, Artur. "Differences of Opinion Make a Horse Race." Rev. Financial Studies (1993), in press.

Harrison, J. Michael, and Kreps, David M. "Martingales and Arbitrage in Multiperiod Securities Markets." J. Econ. Theory 20 (June 1979): 381-408.

He, H., and Wang, Jiang. "Differential Information and Dynamic Behavior of Trading Volume." Manuscript. Cambridge: Massachusetts Inst. Tech., 1992.

Heaton, John, and Lucas, Deborah J. "Evaluating the Effects of Incomplete Markets on Risk Sharing and Asset Pricing." Working Paper no. 4249. Cambridge, Mass.: NBER, January 1993.

Huffman, Gregory W. "A Dynamic Equilibrium Model of Asset Prices and Transaction Volume." J.P.E. 95 (February 1987): 138-59.

Jazwinski, Andrew H. Stochastic Processes and Filtering Theory. New York: Academic Press, 1970.

Kandel, E., and Pearson, N. D. "Differential Interpretation of Public Signals and Trade in Speculative Markets." Manuscript. Rochester, N.Y.: Univ. Rochester, 1993.

Karpoff, Jonathan M. “A Theory of Trading Volume.” J. Finance 41 (December 1986): 1069-87.

— "The Relation between Price Changes and Trading Volume: A Survey." J. Financial and Quantitative Analysis 22 (March 1987): 109-26.

Kiger, Jack E. "An Empirical Investigation of NYSE Volume and Price Reactions to the Announcement of Quarterly Earnings." J. Accounting Res. 10 (Spring 1972): 113-28.

Kim, O., and Verrecchia, Robert E. "Market Reaction to Anticipated Announcements." J. Financial Econ. 30 (December 1991): 273-309.

Kyle, Albert S. "Continuous Auctions and Insider Trading." Econometrica 56 (November 1985): 1315-35.

LeBaron, Blake. "Persistence of the Dow Jones Index on Rising Volume." Manuscript. Madison: Univ. Wisconsin, 1992.

Lucas, Deborah J. "Asset Pricing with Undiversifiable Income Risk and Short Sales Constraints: Deepening the Equity Premium Puzzle." Manuscript. Evanston, Ill.: Northwestern Univ., 1991.

Lucas, Robert E., Jr. "Asset Prices in an Exchange Economy." Econometrica 46 (November 1978): 1429-45.

Mankiw, N. Gregory. "The Equity Premium and the Concentration of Aggregate Shocks." J. Financial Econ. 17 (September 1986): 211-19.

Marcet, Albert, and Singleton, Kenneth J. "Equilibrium Asset Prices and Savings of Heterogeneous Agents in the Presence of Incomplete Markets and Portfolio Constraints." Manuscript. Stanford, Calif.: Stanford Univ., 1991.

Merton, Robert C. "Lifetime Portfolio Selection under Uncertainty: The Continuous-Time Case." Rev. Econ. and Statis. 51 (August 1969): 247-57. 
“An Intertemporal Capital Asset Pricing Model." Econometrica 41 (September 1973): 867-87.

. Continuous-Time Finance. Oxford: Blackwell, 1990.

Michaely, Roni, and Vila, Jean-Luc. "Investors' Heterogeneity and Prices and Volume around the Ex-Dividend Day." Manuscript. Ithaca, N.Y.: Cornell Univ., 1993.

Morse, Dale. "Asymmetrical Information in Securities Markets and Trading Volume." J. Financial and Quantitative Analysis 15 (December 1980): $1129-48$.

Pfleiderer, Paul. "The Volume of Trade and the Variability of Prices: A Framework for Analysis in Noisy Rational Expectations Equilibria." Manuscript. Stanford, Calif.: Stanford Univ., 1984.

Scheinkman, José A., and Weiss, Laurence. "Borrowing Constraints and Aggregate Economic Activity." Econometrica 54 (January 1986): 23-45.

Varian, Hal R. "Divergence of Opinion in Complete Markets: A Note." $J$. Finance 40 (March 1985): 309-17.

Wang, Jiang. "A Model of Intertemporal Asset Prices under Asymmetric Information." Rev. Econ. Studies 60 (April 1993): 249-82. 